\title{
Stainless steel plate girders subjected to shear buckling at normal and elevated temperatures
}

\author{
André Reis ${ }^{\mathrm{a}}$, Nuno Lopes ${ }^{\mathrm{a}}$, Esther Real ${ }^{\mathrm{b}}$, Paulo Vila Real ${ }^{\mathrm{a}}$ \\ a RISCO - University of Aveiro, Department of Civil Engineering, Campus Universitário de Santiago, \\ 3810-193 Aveiro, Portugal; Telephone number. +351 234370942; Fax number +351 234370094 \\ ${ }^{\mathrm{b}}$ Department of Construction Engineering, Universitat Politècnica de Catalunya, UPC, 08034 Barcelona, \\ Spain
}

Keywords: Numerical validation, Experimental tests, Shear buckling, Stainless steel, Geometric imperfections, Residual stresses, Fire.

\begin{abstract}
Plate girders are widely used as structural members in the steel construction industry because of their ability to support heavy loads over long spans. Therefore, it is very important to know their behaviour under different conditions. For material efficiency, plate girders usually have slender webs when compared to the ones on commercial hot rolled profiles, making them prone to the occurrence of shear buckling. In case of fire, shear buckling may be precipitated due to the reduction of the steel mechanical properties caused by the elevated temperatures. Regarding the resistance determination, numerical simulation has been gaining an edge on experimental analysis over the past years, mainly due to the high cost of the fire resistance experimental tests. However, the numerical models must be properly validated in order to perform reliable numerical
\end{abstract}


studies. With this purpose, as no experimental tests in stainless steel plate girders subjected to elevated temperatures were found, a total of 34 experimental tests at normal temperature have been numerically modelled. The tested stainless steel plate girders had different configurations, provided with transversal and longitudinal stiffeners. Comparative analyses between those experimental and numerical results have been done. Afterwards, the developed numerical model has been used to perform a sensitivity analysis on the influence of the initial geometric imperfections at both normal and elevated temperatures, considering different values for its amplitudes. The effect of the residual stresses has also been analysed at normal temperature and in case of fire. Finally, comparisons between the numerical results and the Eurocode 3 design procedures have been performed.

\section{Introduction}

Steel plate girders are commonly used in Civil Engineering, mainly in bridges and in buildings when it is required to support heavy concentrate loads over long spans.A plate girder is basically an I-beam assembled from steel plates which are welded to one another. As earlier stated, it is a structural member used to carry loads which cannot be economically carried by hot rolled beams. Standard hot rolled cross-sections may be adequate for many of the usual structures, but in situations where the load is heavier and the span is also large, its application is usually uneconomical. In those cases, designer frequently opts to use a fabricated plate girder choosing the size of web and flanges. Generally, plate girders have slender webs, which are extremely susceptible to the occurrence of shear buckling, and they are often provided with intermediate and end stiffeners to benefit the post buckling strength of the webs. 
Even though the initial cost of structural stainless steel is higher than carbon steel, it has various desirable characteristics for a structural material [1,2]. The main advantage of stainless steel is its high resistance to corrosion. Low alloyed grades resist corrosion in atmospheric conditions and highly alloyed grades can resist corrosion in most severe environments. Stainless steel is also a durable and low maintenance material, being often the least expensive choice in a life cycle cost comparison. Additionally, its aesthetic appearance and its smaller need for thermal protection are other factors for improving stainless steel competitiveness in steel construction industry. These favourable features have positively encouraged the use of stainless steel in construction during recent decades but, even if its use is increasing, it is nevertheless still necessary to develop the knowledge on its structural behaviour, particularly at elevated temperatures.

In the last years, as the methods for the design of carbon steel structures subjected to shear buckling at normal temperature are more stablished, the stainless steel has become the focus of the shear buckling study at normal temperature. Traditionally, the stainless steel design rules have been based on analogies with those adopted for carbon steel, with some adjustments made when necessary to fit with test results. In 2001 Olsson's investigation [3] provided a method based on the Rotated Stress Field Method [4] with some modifications in the expressions for the shear buckling reduction factor and in the definition of the distance where the plastic hinges appear. This method was included in Part 1-4 of EC3 [5] for the design of stainless steel plate girders subjected to shear buckling. However, the behaviour of stainless steel plate girders in fire situation has not been receiving the appropriated attention and the accuracy of the application of the existing design expressions for normal temperature adapted to elevated temperatures must be studied. 
Fire is one of the most serious environmental hazards to which a steel structure can be subjected during its lifetime [6,7]. Indeed, this accidental action may cause a severe impact on a steel structure, resulting in significant economic and public losses. In the last years there have been several fires in bridges with some of them causing the collapse of steel girders [8].

Performing fire resistance experimental tests is very expensive. For this reason, the FEM modelling has been growing up in the past few years, with several research activities being conducted based on numerical simulation. However, it is still necessary to validate the numerical models. Hence, a total of thirty-four experimental tests [3,913] at normal temperature carried out on stainless steel plate girders were reproduced. No experimental tests in stainless steel plate girders subjected to elevated temperatures were found. For the validation of the numerical model, comparisons between the experimental and the numerical results were performed. Afterwards, sensitivity analyses at both normal and elevated temperatures were made in order to know the influence of the geometric imperfections, considering different maximum amplitudes, and the influence of residual stresses on the ultimate shear strength of stainless steel plate girders, analysing plate girders with and without residual stresses. For the numerical modelling it was used SAFIR [14,15], a computer software developed at University of Liège for the simulation of the behaviour of structures subjected to fire.

Finally, as no specific design procedures for the ultimate shear strength verification at elevated temperatures are given in Part 1-2 of EC3 [16], the application of the shear design rules at normal temperature, according to Part 1-4 of EC3 [5], adapted to fire design by the direct application of the reduction factors for the steel stress-strain relationship at elevated temperatures [16], was also studied. 


\section{Review of experimental tests}

In order to better understand the behaviour of stainless steel plate girders, a numerical model was validated against existing experimental data. Therefore, the experimental tests used in this study are described in this section. The material properties, as well as the geometric characteristics and the set-up of the tested girders, are also here presented.

Several experimental campaigns in stainless steel plate girders were conducted at Polytechnic University of Catalunya (UPC) [9-11]. A total of nineteen specimens with different configurations are analysed in this paper. The girders were tested as simply supported elements subjected to a concentrated load at mid-span. The first campaign was conducted by Real et al. [9] in plate girders with non-rigid end posts and the geometry of the tested girders in this campaign is presented in Figure 1. The second experimental campaign was carried out by Estrada et al. [10] in eight stainless steel plate girders with non-rigid (see Figure 1) and rigid end posts (see Figure 2). The main goal was to study the influence of the rigid end post on the ultimate shear strength of plate girders. The third campaign analysed the behaviour of an intermediate panel in comparison with an end panel [11]. With that purpose, two four-panels plate girders were tested with the geometry presented in Figure 3. Finally, the last experimental campaign analysed in this paper on stainless steel plate girders performed at UPC intended to study the influence of the longitudinal stiffening on the ultimate shear capacity of the beams [11]. The geometry of the tested girders is presented in Figure 4. The dimensions and the material properties of the tested girders are presented in Table 1and Table 2, respectively. The stainless steel grade was 1.4301 . 


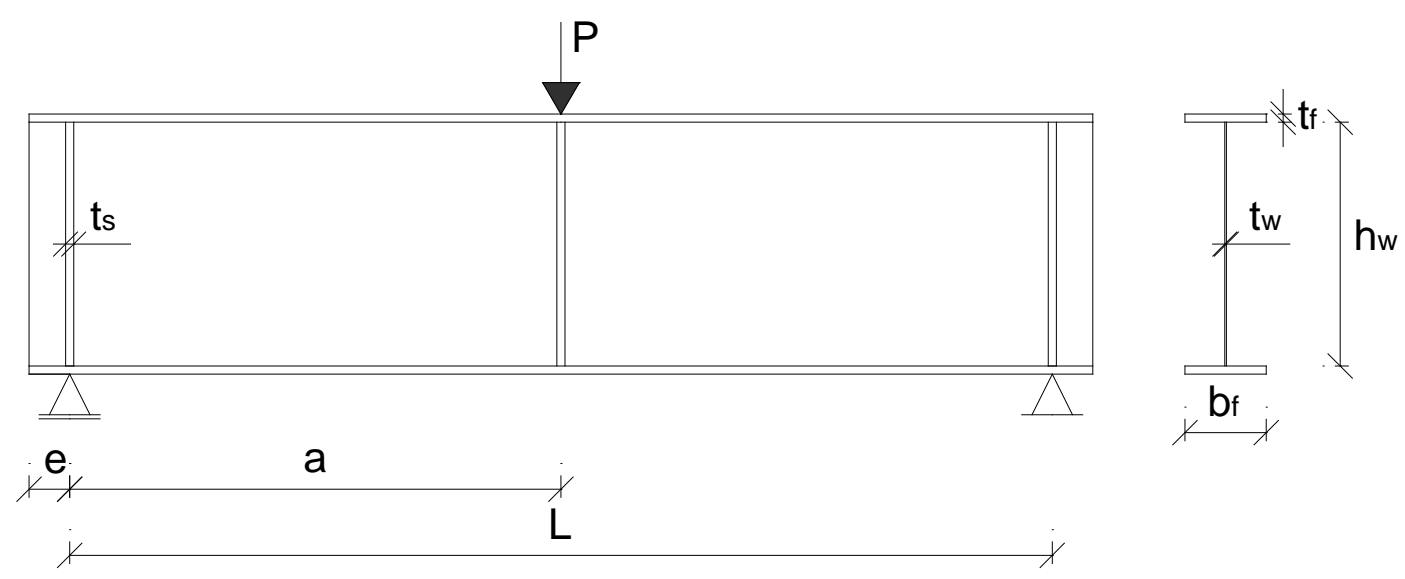

Figure 1 - Geometry of the tested girders with non-rigid end posts (PG1-5, PG7, PG9,

$$
\text { PG11) }
$$

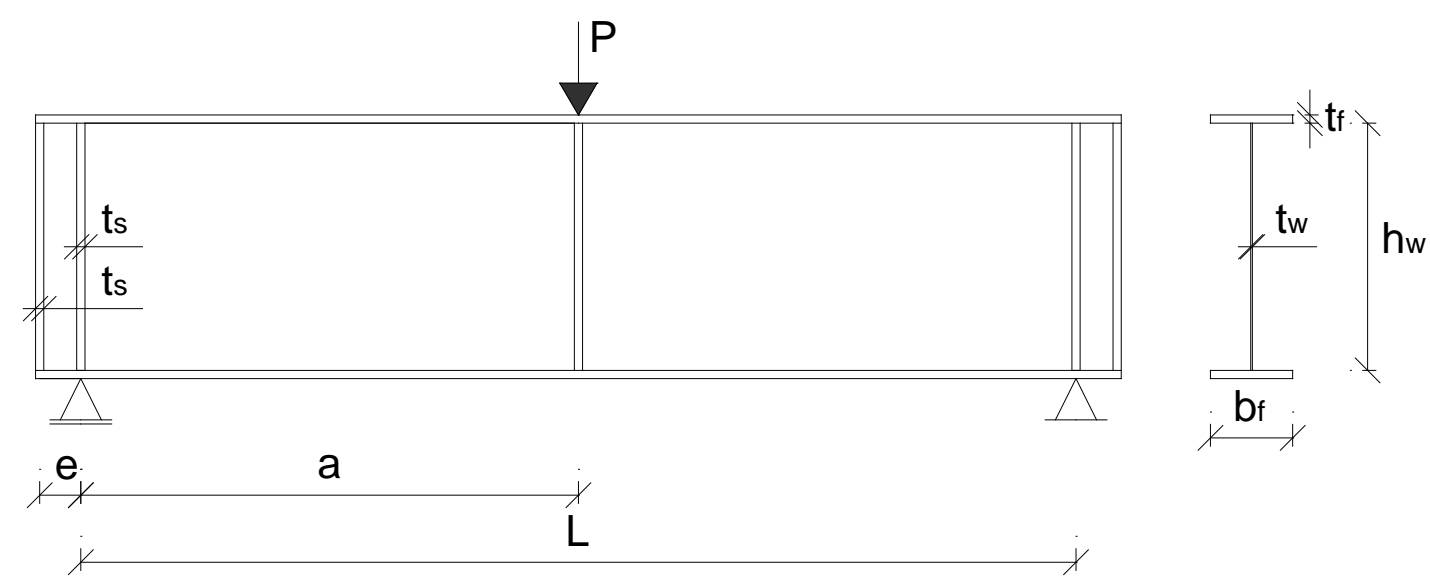

Figure 2 - Geometry of the tested girders with rigid end posts (PG6, PG8, PG10, PG12,

PG20-28)

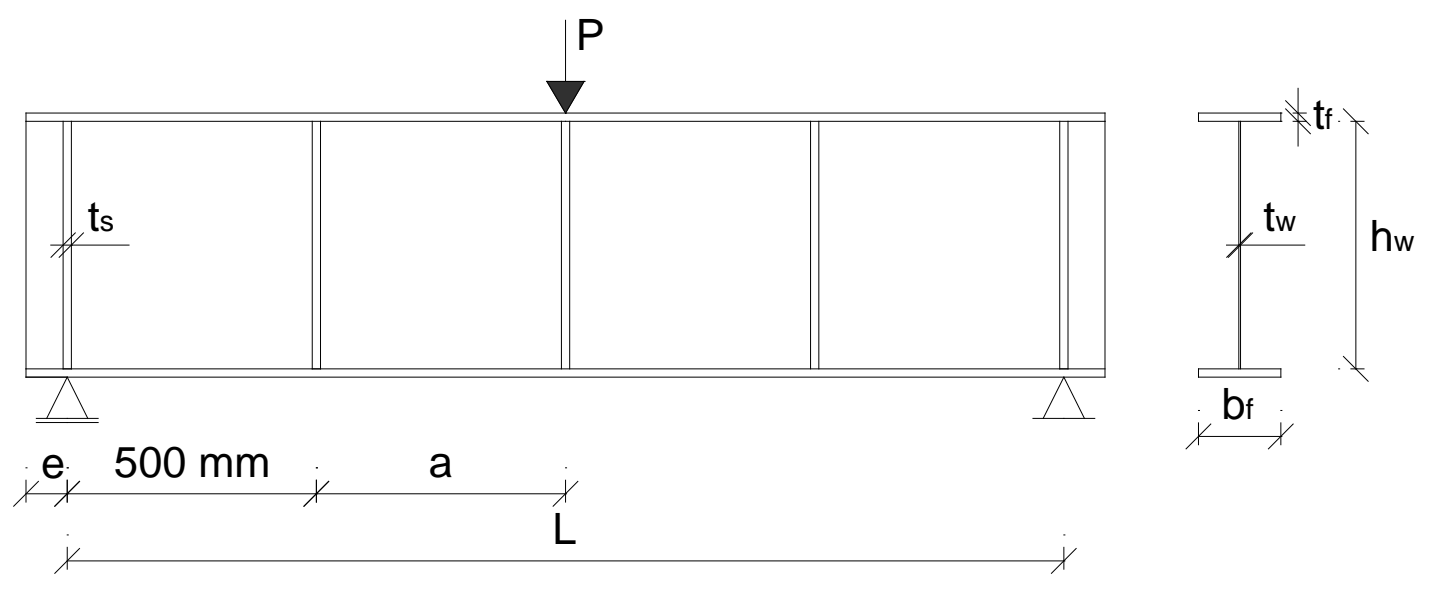

Figure 3 - Geometry of the 4-panels tested girders (PG13 and PG14) 


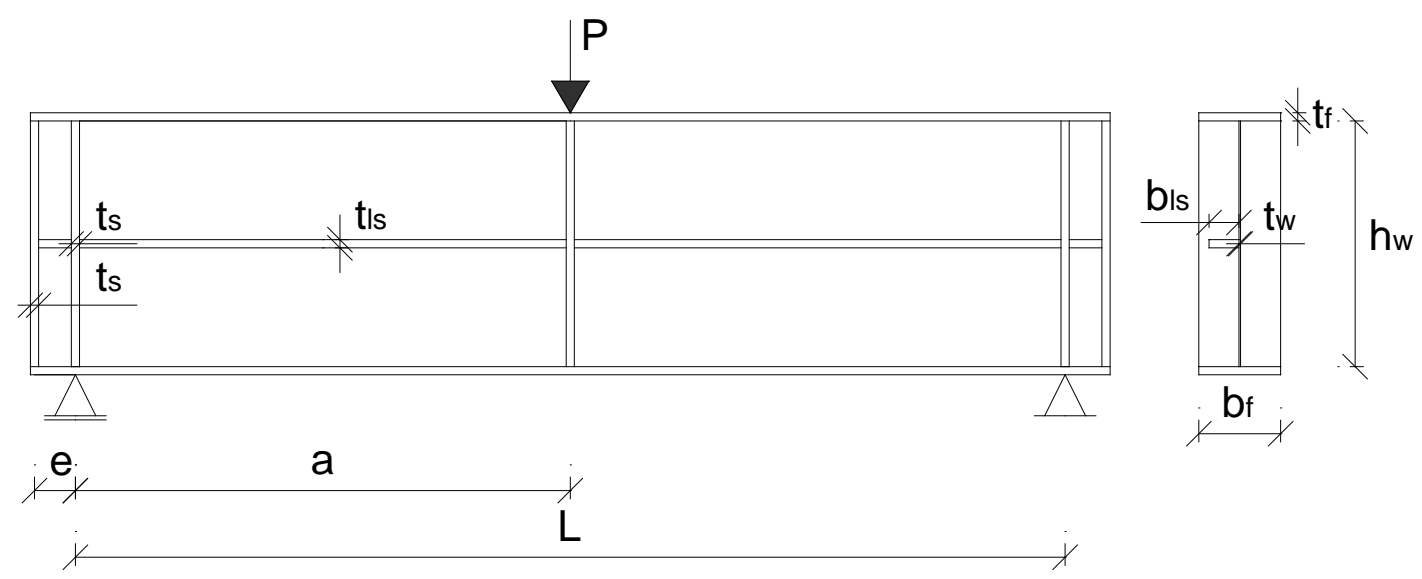

Figure 4 - Geometry of the longitudinally stiffened tested girders (PG15-19)

Recently, an experimental campaign in lean duplex stainless steel (1.4162) plate girders was carried out at Imperial College London. This experimental campaign is fully described in [12]. A total of nine plate girders were tested with the geometry presented in Figure 2. The girders were simply supported and the load was applied at the midspan. Table 1shows the dimensions of the tested girders and the material properties are presented in Table 2.

In 2001, an experimental campaign in stainless steel plate girders was performed at Lulea University of Technology. A fully description of these tests can be found in [3]. The plate girders were simply supported and had no end posts, as shown in Figure 5. The load was applied at the position of the intermediate transverse stiffener. The girders dimensions are presented in Table 1, whereas Table 2 shows the material properties. The stainless steel grade was 1.4301 for PG29-31 and 1.4462 for PG32-34. As no information was found in [3], the values of the ultimate strength $\left(\sigma_{\mathrm{m}}\right)$ were obtained according to Equation 1 [17,18]. The Young's modulus was considered equal to 200 GPa.

$\sigma_{m}=\frac{\sigma_{0.2}}{0.2+185 \sigma_{0.2} / \mathrm{E}}$ 


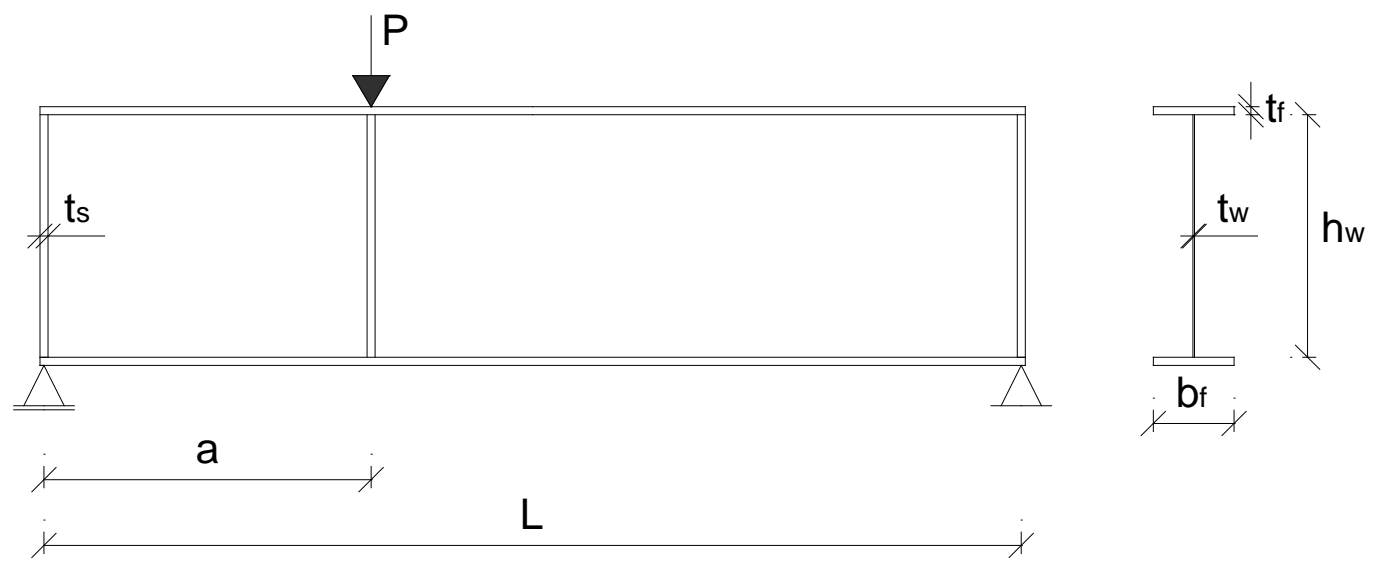

Figure 5 - Geometry of the girders tested by Olsson (PG29-34) 
Table 1 - Stainless steel girders dimensions

\begin{tabular}{|c|c|c|c|c|c|c|c|c|c|c|c|c|c|}
\hline Label & Reference & $\begin{array}{c}\mathrm{T} \\
{\left[{ }^{\circ} \mathrm{C}\right]}\end{array}$ & $\begin{array}{c}\mathrm{L} \\
{[\mathrm{mm}]}\end{array}$ & $\begin{array}{c}\mathrm{a} \\
{[\mathrm{mm}]}\end{array}$ & $\begin{array}{c}\mathrm{e} \\
{[\mathrm{mm}]}\end{array}$ & {$\left[\begin{array}{c}\mathrm{h}_{\mathrm{w}} \\
{[\mathrm{mm}]}\end{array}\right.$} & $\begin{array}{c}\mathrm{t}_{\mathrm{w}} \\
{[\mathrm{mm}]}\end{array}$ & $\begin{array}{c}\mathrm{b}_{\mathrm{f}} \\
{[\mathrm{mm}]}\end{array}$ & $\begin{array}{c}\mathrm{t}_{\mathrm{f}} \\
{[\mathrm{mm}]}\end{array}$ & $\mid \begin{array}{c}\mathrm{t}_{\mathrm{s}} \\
{[\mathrm{mm}]}\end{array}$ & {$\left[\begin{array}{c}\mathrm{t}_{\mathrm{ss}} \\
{[\mathrm{mm}]}\end{array}\right.$} & $\begin{array}{c}\mathrm{b}_{\mathrm{ls}} \\
{[\mathrm{mm}]}\end{array}$ & $\begin{array}{c}\mathrm{a} / \mathrm{h}_{\mathrm{w}} \\
{[-]}\end{array}$ \\
\hline PG1 & \multirow{4}{*}{$\begin{array}{c}\text { Real et al. } \\
\text { [9] }\end{array}$} & 20 & 1000 & 500 & 100 & 1000 & 4.0 & 200 & 20.0 & 20.0 & - & - & 0.50 \\
\hline PG2 & & 20 & 1000 & 500 & 100 & 500 & 4.0 & 200 & 20.0 & 20.0 & - & - & 1.00 \\
\hline PG3 & & 20 & 1500 & 750 & 100 & 500 & 4.0 & 200 & 20.0 & 20.0 & - & - & 1.50 \\
\hline PG4 & & 20 & 2000 & 1000 & 100 & 500 & 4.0 & 200 & 20.0 & 20.0 & - & - & 2.00 \\
\hline PG5 & \multirow{8}{*}{$\begin{array}{l}\text { Estrada et } \\
\text { al. [10] }\end{array}$} & 20 & 2100 & 1050 & 130 & 700 & 4.0 & 200 & 20.0 & 20.0 & - & - & 1.50 \\
\hline PG6 & & 20 & 2100 & 1050 & 130 & 700 & 4.0 & 200 & 20.0 & 20.0 & - & - & 1.50 \\
\hline PG7 & & 20 & 2400 & 1200 & 130 & 600 & 4.0 & 200 & 20.0 & 20.0 & - & - & 2.00 \\
\hline PG8 & & 20 & 2400 & 1200 & 130 & 600 & 4.0 & 200 & 20.0 & 20.0 & - & - & 2.00 \\
\hline PG9 & & 20 & 2500 & 1250 & 130 & 500 & 4.0 & 200 & 20.0 & 20.0 & - & - & 2.50 \\
\hline PG10 & & 20 & 2500 & 1250 & 130 & 500 & 4.0 & 200 & 20.0 & 20.0 & - & - & 2.50 \\
\hline PG11 & & 20 & 2600 & 1300 & 130 & 400 & 4.0 & 200 & 20.0 & 20.0 & - & - & 3.25 \\
\hline PG12 & & 20 & 2600 & 1300 & 130 & 400 & 4.0 & 200 & 20.0 & 20.0 & - & - & 3.25 \\
\hline PG13 & \multirow{7}{*}{$\begin{array}{c}\text { Estrada } \\
\text { [11] }\end{array}$} & 20 & 2000 & 500 & 100 & 500 & 4.0 & 200 & 20.0 & 20.0 & - & - & 1.00 \\
\hline PG14 & & 20 & 3000 & 750 & 100 & 500 & 4.0 & 200 & 20.0 & 20.0 & - & - & 1.50 \\
\hline PG15 & & 20 & 2100 & 1050 & 130 & 700 & 4.0 & 200 & 20.0 & 20.0 & 8.0 & 25 & 1.50 \\
\hline PG16 & & 20 & 2100 & 1050 & 130 & 700 & 4.0 & 200 & 20.0 & 20.0 & 8.0 & 40 & 1.50 \\
\hline PG17 & & 20 & 2100 & 1050 & 130 & 700 & 4.0 & 200 & 20.0 & 20.0 & 8.0 & 50 & 1.50 \\
\hline PG18 & & 20 & 2100 & 1050 & 130 & 700 & 4.0 & 200 & 20.0 & 20.0 & 8.0 & 100 & 1.50 \\
\hline PG19 & & 20 & 2100 & 1050 & 130 & 700 & 4.0 & 200 & 20.0 & 20.0 & 20.0 & 50 & 1.50 \\
\hline PG20 & \multirow{9}{*}{$\begin{array}{c}\text { Saliba } \\
\text { and } \\
\text { Gardner } \\
\text { [12] }\end{array}$} & 20 & 1200 & 600 & 80 & 600 & 4.1 & 200 & 12.4 & 20.9 & - & - & 1.00 \\
\hline PG21 & & 20 & 1200 & 600 & 80 & 600 & 6.2 & 200 & 12.3 & 20.6 & - & - & 1.00 \\
\hline PG22 & & 20 & 1200 & 600 & 80 & 600 & 8.2 & 200 & 12.5 & 20.6 & - & - & 1.00 \\
\hline PG23 & & 20 & 1200 & 600 & 80 & 600 & 10.2 & 200 & 12.4 & 20.6 & - & - & 1.00 \\
\hline PG24 & & 20 & 2400 & 1200 & 80 & 600 & 4.1 & 200 & 12.6 & 20.8 & - & - & 2.00 \\
\hline PG25 & & 20 & 2400 & 1200 & 80 & 600 & 6.0 & 200 & 12.3 & 20.8 & - & - & 2.00 \\
\hline PG26 & & 20 & 2400 & 1200 & 80 & 600 & 8.4 & 200 & 12.3 & 20.6 & - & - & 2.00 \\
\hline PG27 & & 20 & 2400 & 1200 & 80 & 600 & 10.6 & 200 & 12.6 & 20.9 & - & - & 2.00 \\
\hline PG28 & & 20 & 2400 & 1200 & 80 & 600 & 15.0 & 200 & 15.3 & 20.6 & - & - & 2.00 \\
\hline PG29 & \multirow{6}{*}{$\begin{array}{c}\text { Olsson } \\
\text { [3] }\end{array}$} & 20 & 2100 & 900 & 0 & 297 & 4.0 & 200 & 12.0 & 12.0 & - & - & 3.03 \\
\hline PG30 & & 20 & 3000 & 1200 & 0 & 597 & 4.0 & 200 & 12.0 & 12.0 & - & - & 2.01 \\
\hline PG31 & & 20 & 4000 & 1600 & 0 & 793 & 4.0 & 200 & 12.0 & 12.0 & - & - & 2.02 \\
\hline PG32 & & 20 & 2100 & 900 & 0 & 298 & 4.0 & 200 & 12.0 & 12.0 & - & - & 3.02 \\
\hline PG33 & & 20 & 3000 & 1200 & 0 & 597 & 4.0 & 200 & 12.0 & 12.0 & - & - & 2.01 \\
\hline PG34 & & 20 & 4000 & 1600 & 0 & 795 & 4.0 & 200 & 12.0 & 12.0 & - & - & 2.01 \\
\hline
\end{tabular}


Table 2 - Material properties of the stainless steel plate girders

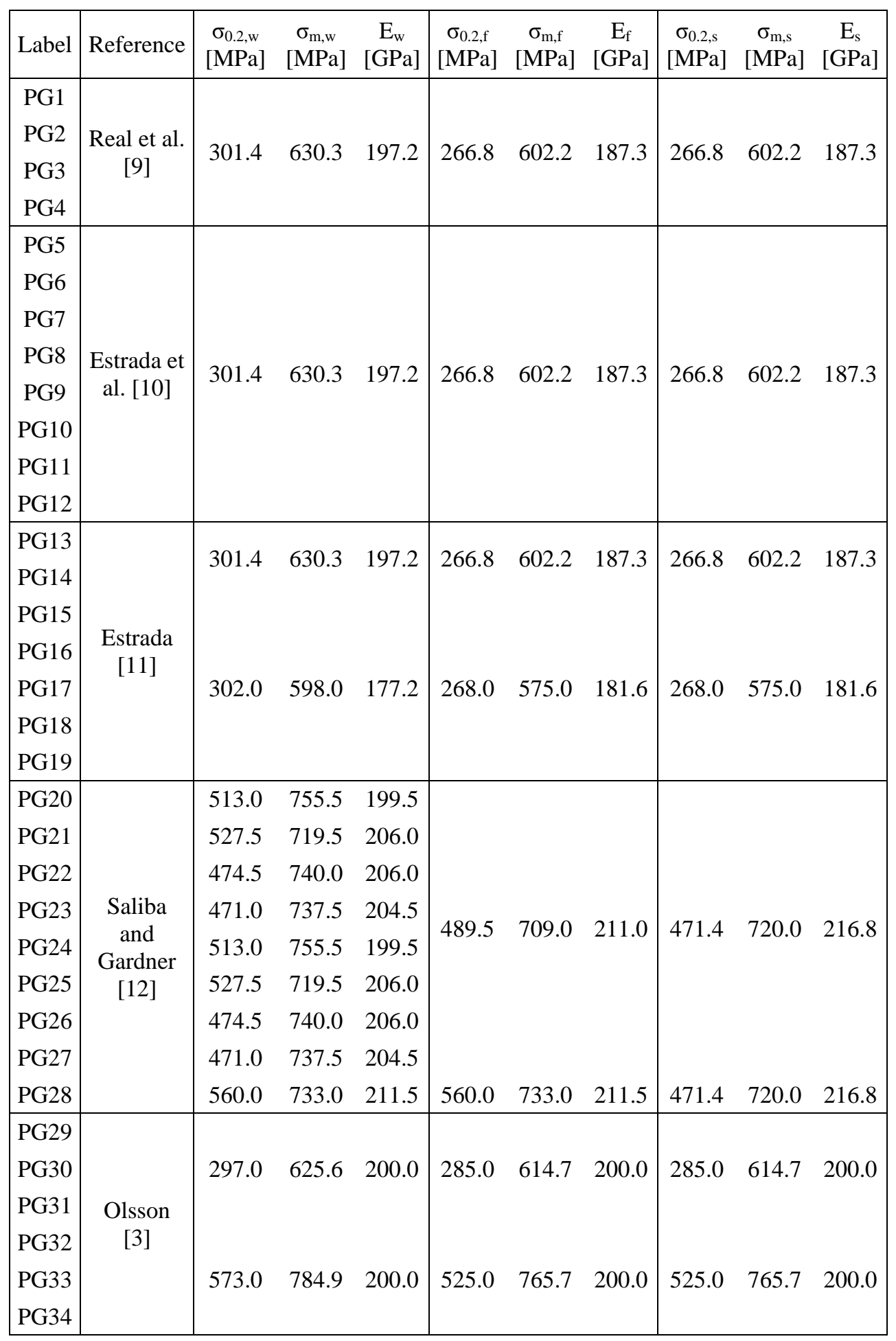




\section{FEM model}

The program SAFIR [14,15] was used in the numerical modelling. A three-dimensional FEM model was developed to perform geometrically and materially nonlinear numerical analyses including imperfections (GMNIA). To better reproduce the local buckling phenomena typical from these slender cross-sections, Quadrangular shell elements with four integration nodes and four levels within the thickness were used. The numerical model is presented in detail in the following sub-sections.

\subsection{Boundary conditions and loading}

The numerical model illustrated in Figure 6 was developed for simply supported plate girders. The boundary conditions are presented in Table 3 and may be observed in Figure 6. Lateral torsional buckling was prevented by constraining the corresponding displacement of points of the upper flange equidistantly at L/10.The loading was applied through the imposition of a concentrated load, being analysed two possibilities. Firstly, on the experimental tests performed at UPC, the loading was applied by the imposition of displacements to better represent the load-deflection experimental curves, being distributed in 3 lines covering all the flange width, as illustrated in Figure 7 a). However, for practical reasons and time efficiency, the aim was to develop a numerical model with imposition of forces which facilitate parametric analyses of the ultimate strength capabilities of the girders, as presented in sections 5 and 6 of this work. Therefore, the loading was also applied through the imposition of forces distributed on the entire web depth (see Figure 7 b)) to avoid loading the upper flanges with variable deformation that did not occur in the experimental tests. 


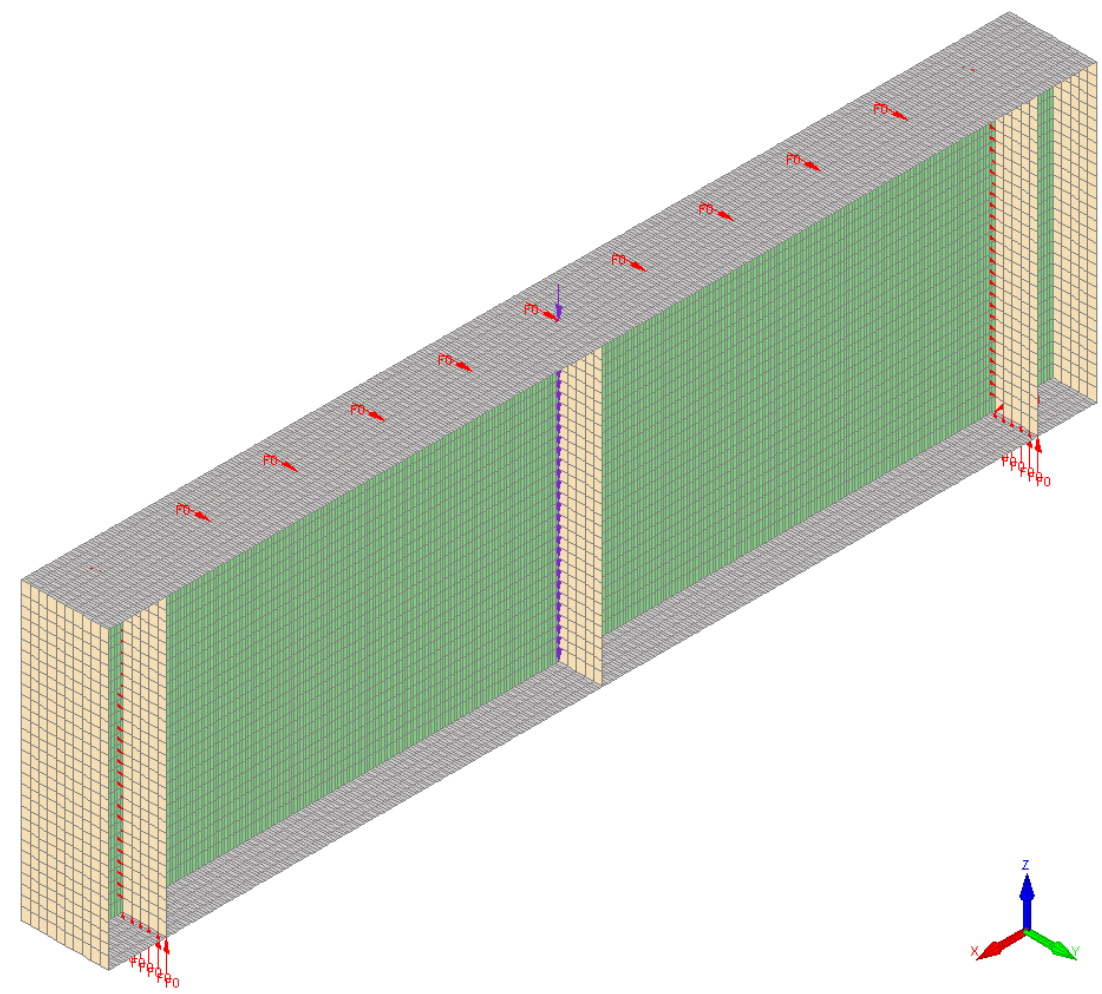

Figure 6 - Numerical model with the boundary conditions and forces imposition

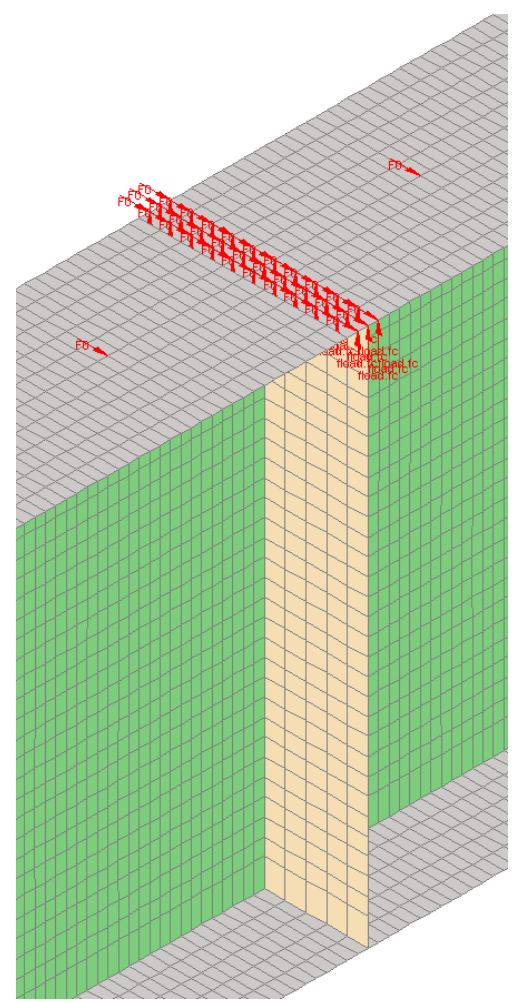

a) displacements imposition

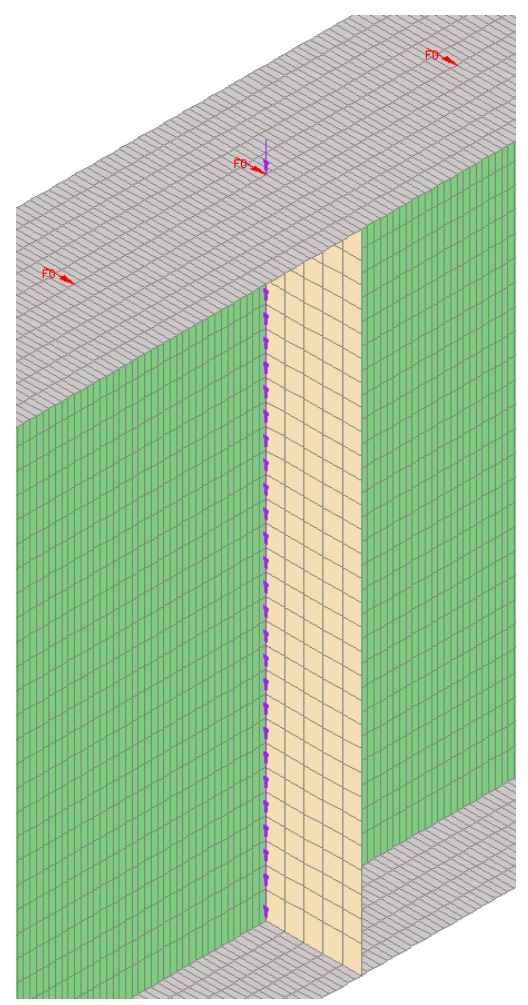

b) forces imposition

Figure 7 - Loading 
Table 3 - Boundary conditions (0-free, 1-fixed)

\begin{tabular}{|c|c|c|c|c|c|c|c|}
\hline \multicolumn{2}{|c|}{ Boundary } & $\Delta_{\mathrm{x}}$ & $\Delta_{\mathrm{y}}$ & $\Delta_{\mathrm{z}}$ & $\theta_{\mathrm{x}}$ & $\theta_{\mathrm{y}}$ & $\theta_{\mathrm{z}}$ \\
\hline \multirow{3}{*}{ Left support } & Web & 0 & 1 & 0 & 0 & 0 & 0 \\
& Lower flange & 0 & 0 & 1 & 0 & 0 & 0 \\
\hline \multirow{2}{*}{ Right support } & Web & 0 & 1 & 0 & 0 & 0 & 0 \\
& Lower flange & 1 & 0 & 1 & 0 & 0 & 0 \\
\hline \multirow{2}{*}{ Lateral bracings } & Upper flange & 0 & 1 & 0 & 0 & 0 & 0 \\
\hline
\end{tabular}

\subsection{Mesh refinement}

A sensitivity analysis considering different mesh refinements was performed in order to find the adequate mesh refinement to achieve reliable results. A mesh refinement with 100 divisions per meter of girder length, 10 divisions in the flanges and 30 divisions in the web, which amounts to 5000 finite elements per meter of girder length, was considered adequate to accurately simulate the plate girder behaviour.

\subsection{Geometric imperfections}

Steel structural members are not perfectly straight due the geometric imperfections caused by the production and fabrication process. These geometric imperfections may cause a significant reduction on the ultimate bearing capacity of the plate girders and consequently it is imperative to take them into account in the numerical modelling. The classical approach to introduce the geometric imperfections into a numerical model is the eigenmodes, which represent the different shapes of imperfections. For this purpose, a linear buckling analysis is firstly performed to found the lowest relevant eigenmode. The obtained shape for the geometric imperfections is incorporated in the non-linear analysis with a chosen maximum amplitude. Since there is no way to occur global buckling on the girders, only local imperfections were introduced in the numerical analysis. The eigenmodes were obtained using the computer programme CAST3M [19] 
and the programme RUBY [20] was used for the interface between CAST3M and SAFIR. The maximum imperfection amplitude was considered the same used by the authors of the experimental tests in their numerical modelling. When there is no information available, the maximum imperfection amplitude was considered equal to $t_{w} / 10$, as used in different studies of plate buckling at normal temperature [21] and at elevated temperature [22]. Figure 8 shows one of the considered buckling modes.

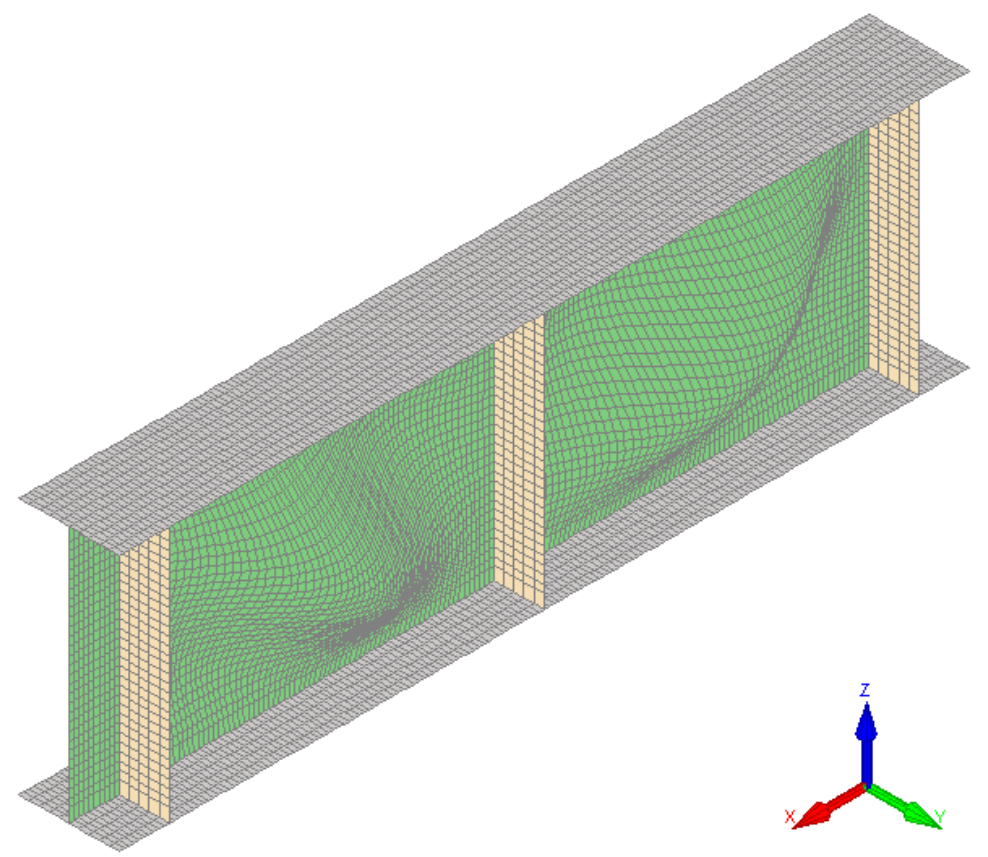

Figure 8 - First buckling mode of PG3

\subsection{Material model}

Stainless steels are known for their non-linear stress-strain relationships with a low conventional limit of proportional stress and an extensive hardening phase [5]. Under normal temperature the approach proposed in Annex C of Part 1-4 of EC3 [5] for the stainless steel stress-strain relationship is based on the Ramberg-Osgood equation. With regard to fire resistance, Part 1-2 of EC3 [16] provides formulae and parameters for the determination of the constitutive law of stainless steel at elevated temperatures (between $20^{\circ} \mathrm{C}$ and $\left.1200^{\circ} \mathrm{C}\right)$. 
As SAFIR is especially devoted to structures in case of fire, it has included the stainless steel stress-strain relationship prescribed in Part 1-2 of EC3 [16], described in Table 4 and in Figure 9. This was the stress-strain relationship applied in this study [23]. When comparing the curves of the constitutive laws of stainless steel, of Part 1-4 and Part 1-2 at $20^{\circ} \mathrm{C}$, one can observe that they are slightly different (see Figure 10 considering the longitudinal direction for the orientation of the steel rolling for Part 1-4 of EC3 law). Previous studies [24] have shown that those differences in the constitutive laws have relatively small influence on the obtained ultimate loads of structural elements subjected to buckling.

Table 4 - Constitutive law expressions of the stainless steel of Part 1-2 of EC3 [16]

\begin{tabular}{|c|c|c|}
\hline Strain range & Stress $\sigma$ & Tangent modulus \\
\hline$\varepsilon \leq \varepsilon_{c, \theta}$ & $\frac{E \cdot \varepsilon}{1+a \cdot \varepsilon^{b}}$ & $\frac{E\left(1+a \cdot \varepsilon^{b}-a \cdot b \cdot \varepsilon^{b}\right)}{\left(1+a \cdot \varepsilon^{b}\right)^{2}}$ \\
\hline$\varepsilon_{c, \theta}<\varepsilon<\varepsilon_{u, \theta}$ & $f_{0.2 p, \theta}-e+(d / c) \sqrt{c^{2}-\left(\varepsilon_{u, \theta}-\varepsilon\right)^{2}}$ & $\frac{d\left(\varepsilon_{u, \theta}-\varepsilon\right)}{c \sqrt{c^{2}-\left(\varepsilon_{u, \theta}-\varepsilon\right)^{2}}}$ \\
\hline Additional parameters and functions are given in Annex C of EN 1993-1-2 \\
\hline
\end{tabular}

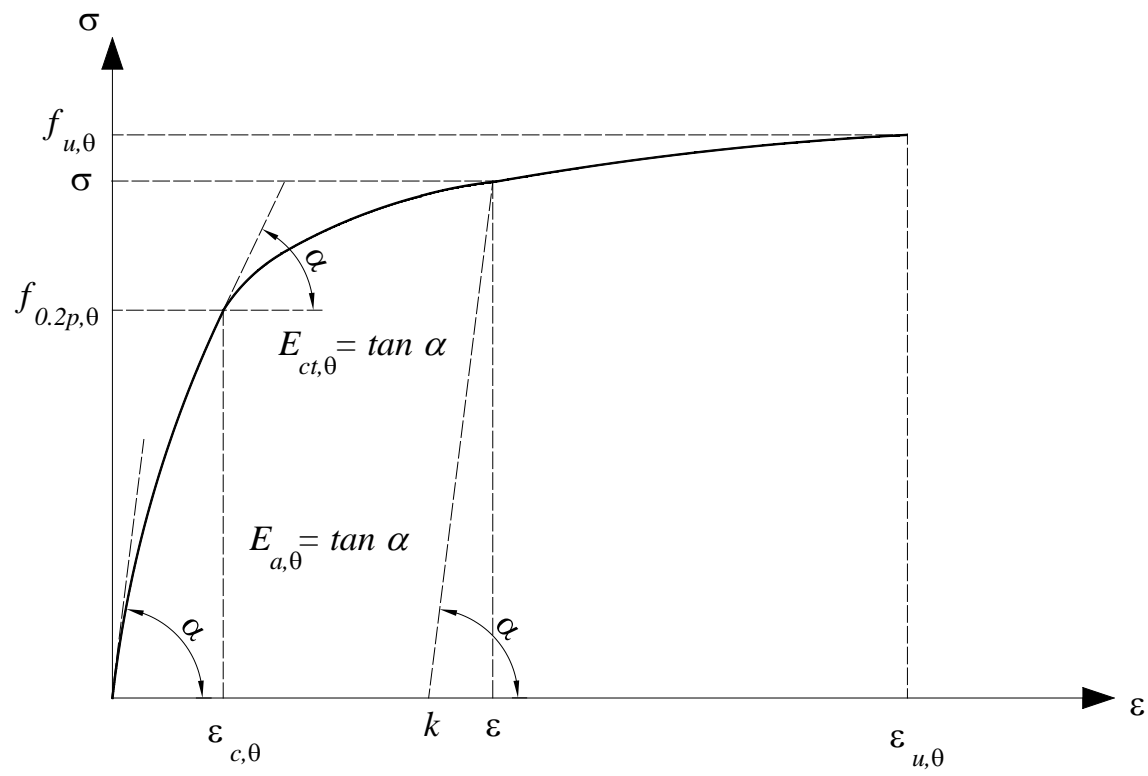

Figure 9 - Stress-strain relationship of the stainless steel in Part 1-2 of EC3 [16] 


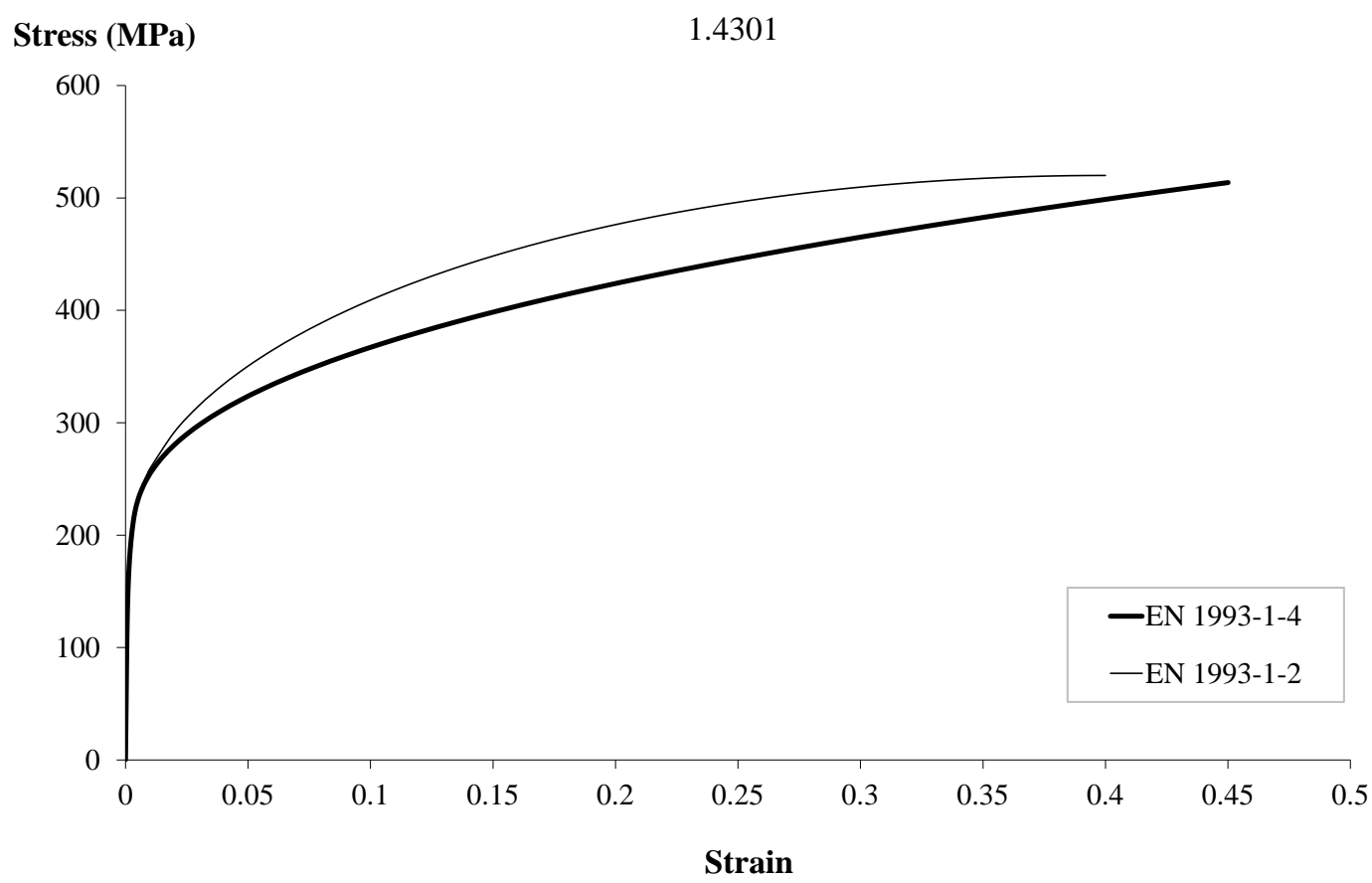

a) stainless steel grade 1.4301

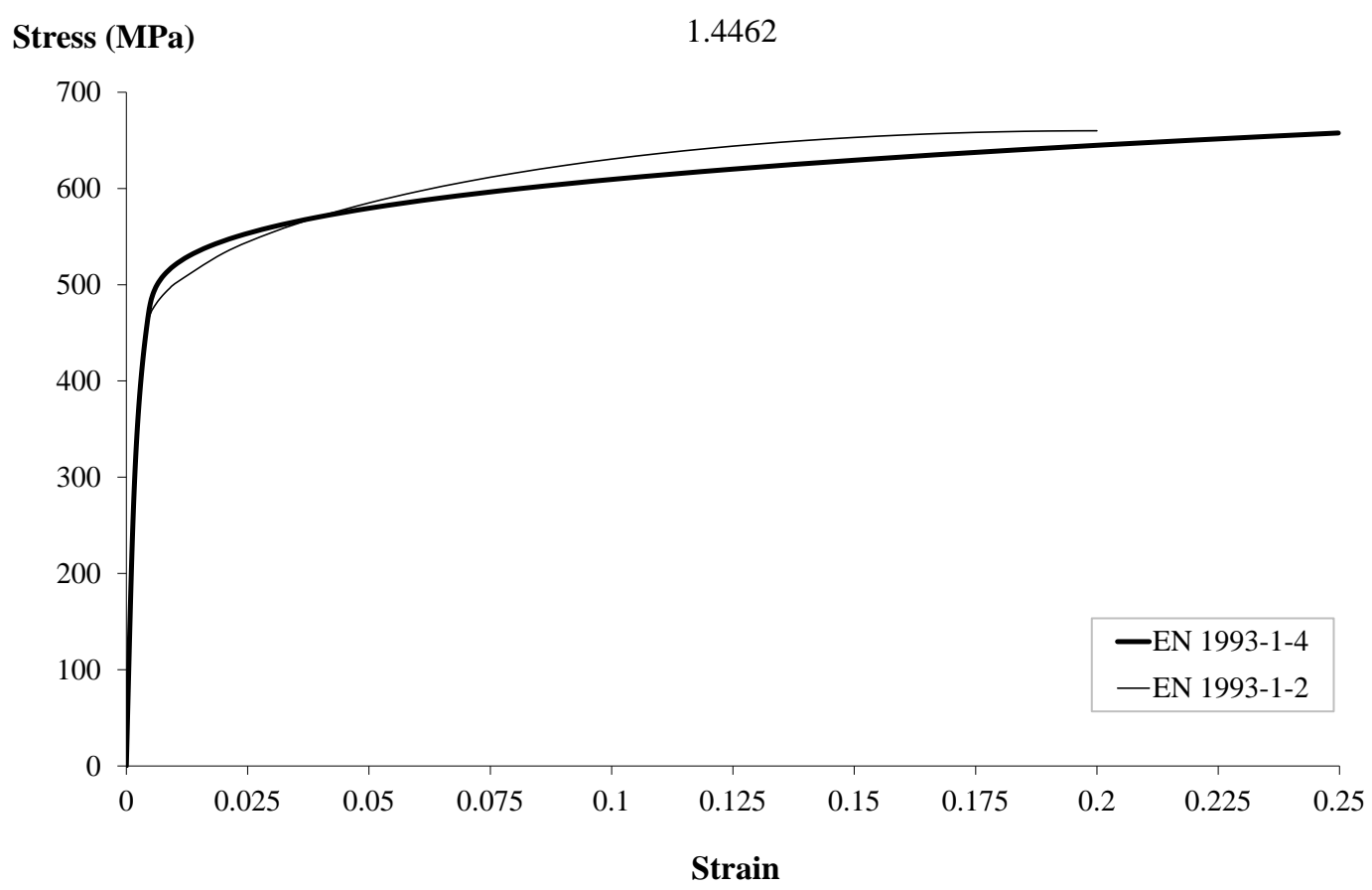

b) stainless steel grade 1.4462

Figure 10 - Comparisons between the stress-strain relationships of the stainless steel in Part 1-4 of EC3 and Part 1-2 of EC3 at $20^{\circ} \mathrm{C}$ 


\section{Discussion of numerical and experimental results}

In this section, the results from the experimental tests and numerical analyses using SAFIR [14,15] are compared. The accuracy of the numerical model is evaluated by performing comparisons based on the experimental and numerical load-deflection curves and failure modes, as well as comparing the ultimate load obtained in both experimental and numerical tests. The ultimate loads numerically obtained by the authors of the experimental tests using ABAQUS [25] are also compared with those obtained using SAFIR.

As presented before, a total of nineteen stainless steel plate girders with different configurations were tested at UPC by Real et al. [9] and Estrada et al. [10,11]. These tests were numerically reproduced by those authors using the ABAQUS software. Figure 11 shows the load deflection curves obtained experimentally and numerically using both ABAQUS and SAFIR software for different configurations of the tested girders. The results from SAFIR presented in Figure 11 were obtained using two different numerical models, as mentioned before. On the one hand, a model with displacements imposition was used in order to have a numerical simulation as similar as possible to the experimental test and the numerical simulation performed using ABAQUS. On the other hand, a model with imposition of forces was used in order to have a numerical model with forces imposition duly validated, which will allow to save time on the numerous parametric analyses that will be conducted in the future, in order to analyse the ultimate resistance of stainless steel plate girders subjected to elevated temperatures and compare the results with the design procedures adopted in the European standards. As one can see, there is a good agreement between the results of SAFIR and the experimental tests in terms of both the initial stiffness and the ultimate strength. The SAFIR and ABAQUS load-deflection curves are also quite close when 
using displacements imposition. It is also important to note that the results obtained using the numerical model with imposition of forces are safe-sided and the ultimate loads are closer to those obtained in the experimental tests.

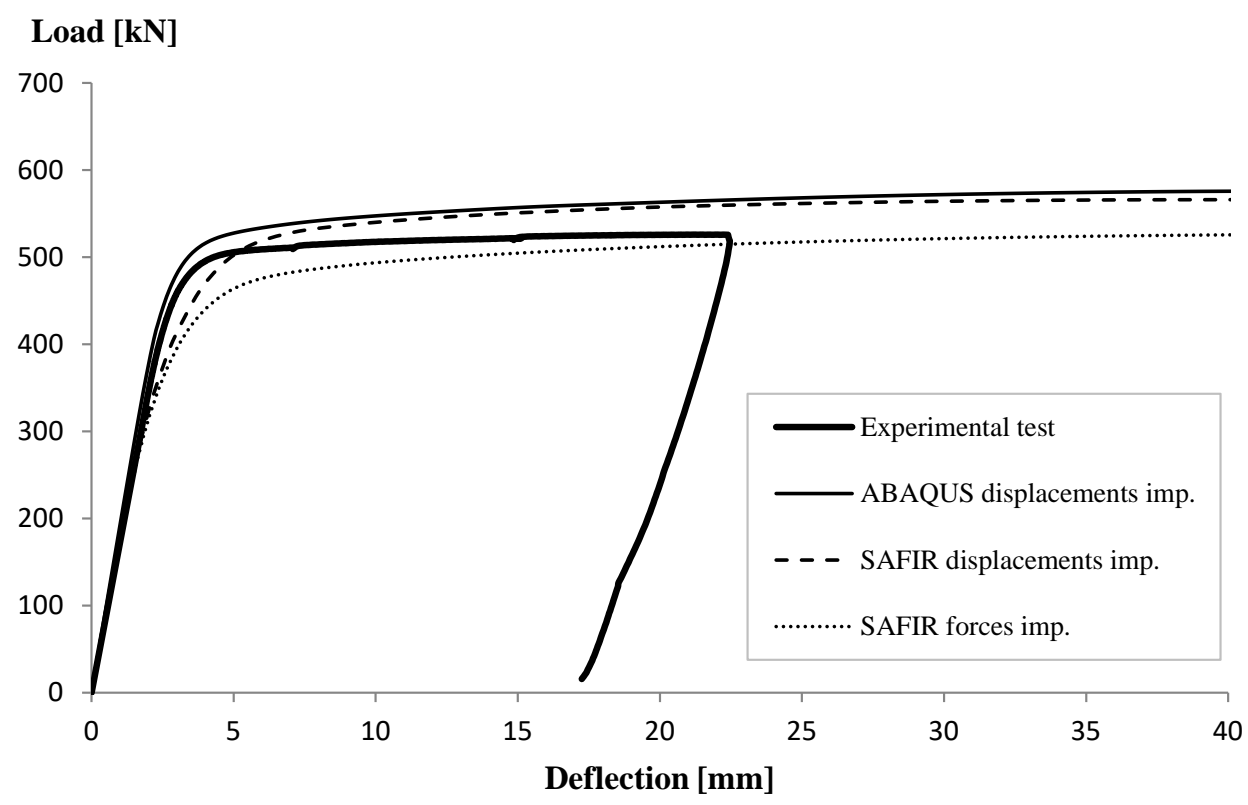

a) PG8 - plate girder with rigid end posts

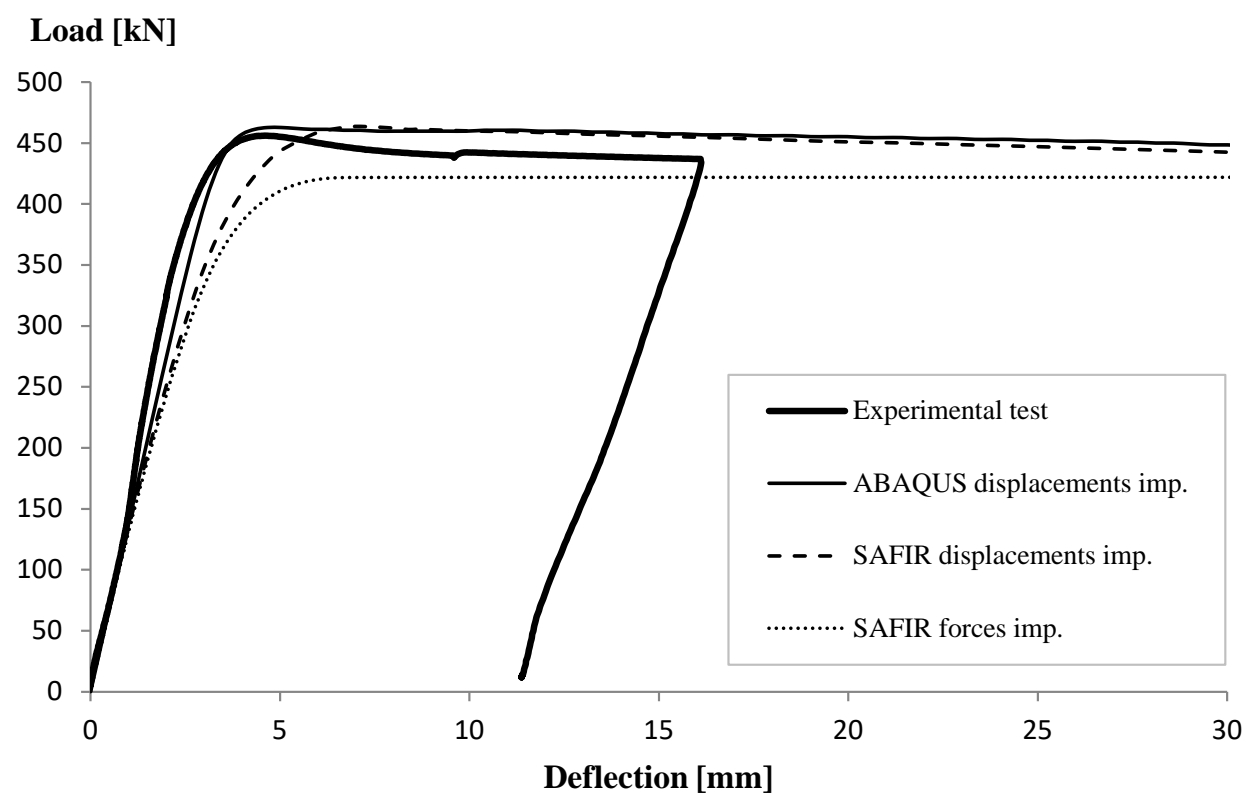

b) PG9 - plate girder with non-rigid end posts 


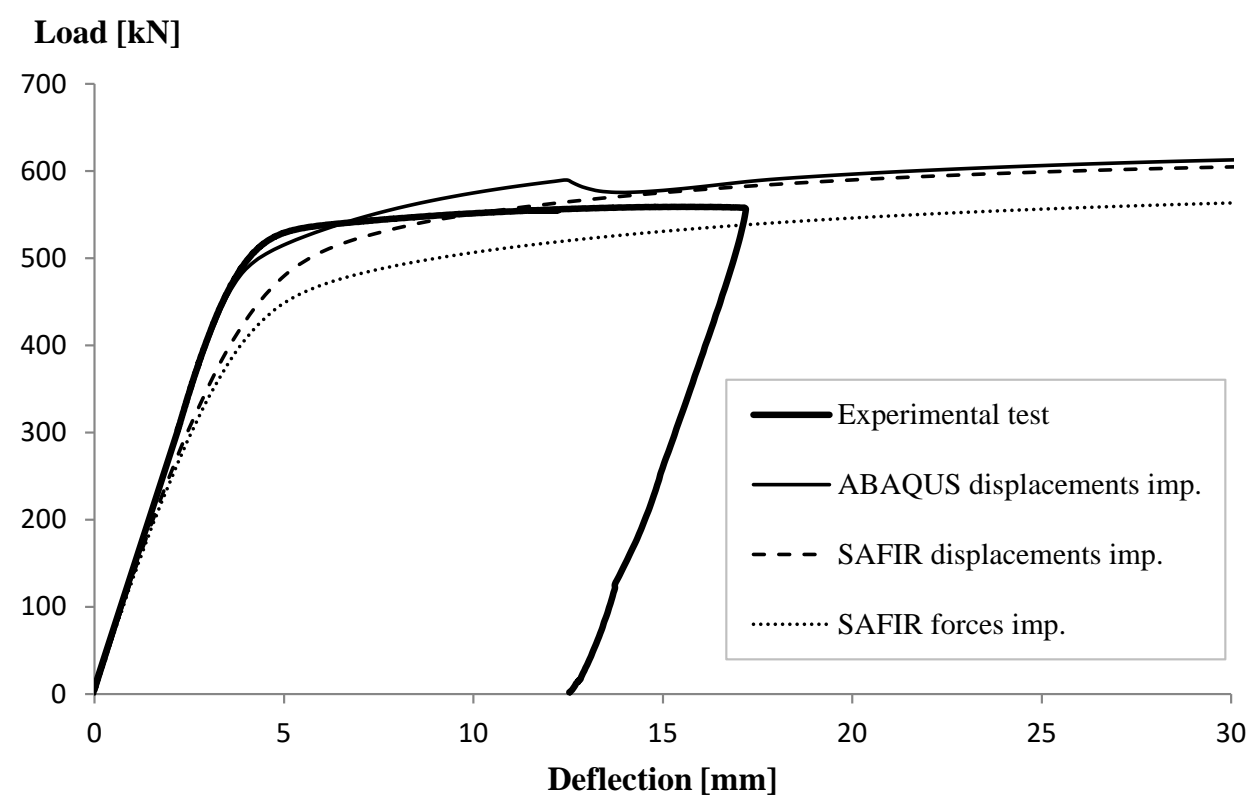

c) PG14 - four-panels plate girder

Figure 11 - Load-deflection curves

Table 5 shows the ultimate loads comparison between both numerical models and the experimental tests, where it is possible to observe that the ultimate loads obtained using the numerical model with displacements imposition are generally higher than those obtained experimentally. On other hand, the numerical model with imposition of forces is on the safe side, this is, the ultimate loads obtained are usually lower than those observed in the experimental tests. This way, the numerical model where the loading is applied through the imposition of forces will be used henceforward. 
Table 5 - Comparison between the numerical models where the loading is applied by imposition of displacements and imposition of forces

\begin{tabular}{|l|ccc|cc|}
\hline \multirow{2}{*}{ Label } & \multicolumn{3}{|c|}{ Ultimate load [kN] } & \multicolumn{2}{c|}{ Safety factor } \\
& Exp. Tests (1) & Displacements (2) & Forces (3) & $(1) /(2)$ & $(1) /(3)$ \\
\hline PG1 & 952.6 & 1066.5 & 986.4 & 0.89 & 0.97 \\
PG2 & 705.0 & 776.5 & 742.8 & 0.91 & 0.95 \\
PG3 & 568.8 & 598.1 & 568.4 & 0.95 & 1.00 \\
PG4 & 485.8 & 505.9 & 474.5 & 0.96 & 1.02 \\
\hline PG5 & 618.4 & 620.9 & 584.0 & 1.00 & 1.06 \\
PG6 & 654.3 & 702.9 & 658.9 & 0.93 & 0.99 \\
PG7 & 521.3 & 530.1 & 487.3 & 0.98 & 1.07 \\
PG8 & 525.8 & 566.0 & 526.3 & 0.93 & 1.00 \\
PG9 & 456.1 & 463.7 & 421.9 & 0.98 & 1.08 \\
PG10 & 473.1 & 471.3 & 430.2 & 1.00 & 1.10 \\
PG11 & 435.8 & 426.7 & 388.5 & 1.02 & 1.12 \\
PG12 & 430.7 & 426.7 & 389.8 & 1.01 & 1.10 \\
\hline PG13 & 714.7 & 773.5 & 740.8 & 0.92 & 0.96 \\
PG14 & 558.9 & 608.8 & 571.4 & 0.92 & 0.98 \\
\hline PG15 & 700.7 & 670.6 & 667.1 & 1.04 & 1.05 \\
PG16 & 764.7 & 695.1 & 694.4 & 1.10 & 1.10 \\
PG17 & 829.0 & 722.7 & 727.5 & 1.15 & 1.14 \\
PG18 & 843.7 & 746.7 & 752.7 & 1.13 & 1.12 \\
PG19 & 843.1 & 763.5 & 780.5 & 1.10 & 1.08 \\
\hline
\end{tabular}

The results using the numerical model with imposition of forces are presented in Table 6 and compared with those obtained from the experimental tests and the numerical analysis in ABAQUS performed by the authors of the experimental tests. The ultimate load values obtained with ABAQUS are usually higher than the experimental ones. However, the results from SAFIR are normally lower than the experimental ones. The mean deviation between the results from the numerical analyses with ABAQUS and the experimental tests is $4.2 \%$, while the mean deviation between SAFIR and experimental results is $5.9 \%$. Therefore, it can be said that the numerical and experimental results agree well and the numerical model developed in SAFIR is on the safe side and may be used for the evaluation of the shear buckling in stainless steel plate girders. 
Table 6 - Ultimate load of the plate girders tested at UPC

\begin{tabular}{|l|ccc|cc|}
\hline \multirow{2}{*}{ Label } & \multicolumn{3}{|c|}{ Ultimate load [kN] } & \multicolumn{2}{c|}{ Deviation [\%] } \\
& Exp. Tests (1) & ABAQUS (2) & SAFIR (3) & (2) vs (1) & (3) vs (1) \\
\hline PG1 & 952.6 & 1054.6 & 986.4 & 10.7 & 3.5 \\
PG2 & 705.0 & 727.2 & 742.8 & 3.1 & 5.4 \\
PG3 & 568.8 & 586.0 & 568.4 & 3.0 & -0.1 \\
PG4 & 485.8 & 510.6 & 474.5 & 5.1 & -2.3 \\
\hline PG5 & 618.4 & 638.4 & 584.0 & 3.2 & -5.6 \\
PG6 & 654.3 & 709.3 & 658.9 & 8.4 & 0.7 \\
PG7 & 521.3 & 541.8 & 487.3 & 3.9 & -6.5 \\
PG8 & 525.8 & 575.8 & 526.3 & 9.5 & 0.1 \\
PG9 & 456.1 & 462.7 & 421.9 & 1.5 & -7.5 \\
PG10 & 473.1 & 465.1 & 430.2 & -1.7 & -9.1 \\
PG11 & 435.8 & 420.8 & 388.5 & -3.4 & -10.9 \\
PG12 & 430.7 & 421.1 & 389.8 & -2.2 & -9.5 \\
\hline PG13 & 714.7 & 754.4 & 740.8 & 5.6 & 3.7 \\
PG14 & 558.9 & 617.1 & 571.4 & 10.4 & 2.2 \\
\hline PG15 & 700.7 & 705.3 & 667.1 & 0.6 & -4.8 \\
PG16 & 764.7 & 782.8 & 694.4 & 2.4 & -9.2 \\
PG17 & 829.0 & 808.2 & 727.5 & -2.5 & -12.2 \\
PG18 & 843.7 & 828.3 & 752.7 & -1.8 & -10.8 \\
PG19 & 843.1 & 849.9 & 780.5 & 0.8 & -7.4 \\
\hline
\end{tabular}

Figure 12 illustrates the deformed shape at the end of the test of a plate girder with nonrigid end posts. It can be seen that both numerical and experimental deformed shapes are very similar. The failure mode is the same and the buckling of the web panel is quite similar, as well as the out of plane displacement of the web in the non-rigid end post. In Figure 13 it is possible to observe the similarity between both numerical and experimental deformed shapes of a plate girder with rigid end posts. The out of plane web buckling of PG7 is presented in Figure 14. It is a common phenomenon in plate girders with non-rigid end posts. Finally, the deformed shape of a plate girder with longitudinal stiffeners is shown in Figure 15. It can be seen that in both cases the buckling wave that forms in the web runs through the longitudinal stiffener because it does not have enough stiffness to allow the formation of a buckling wave in each subpanel of the web as in PG19 (see Figure 16). Based on these comparisons, it can be 
concluded that the numerical model accurately reproduces the response of a plate girder subjected to shear.
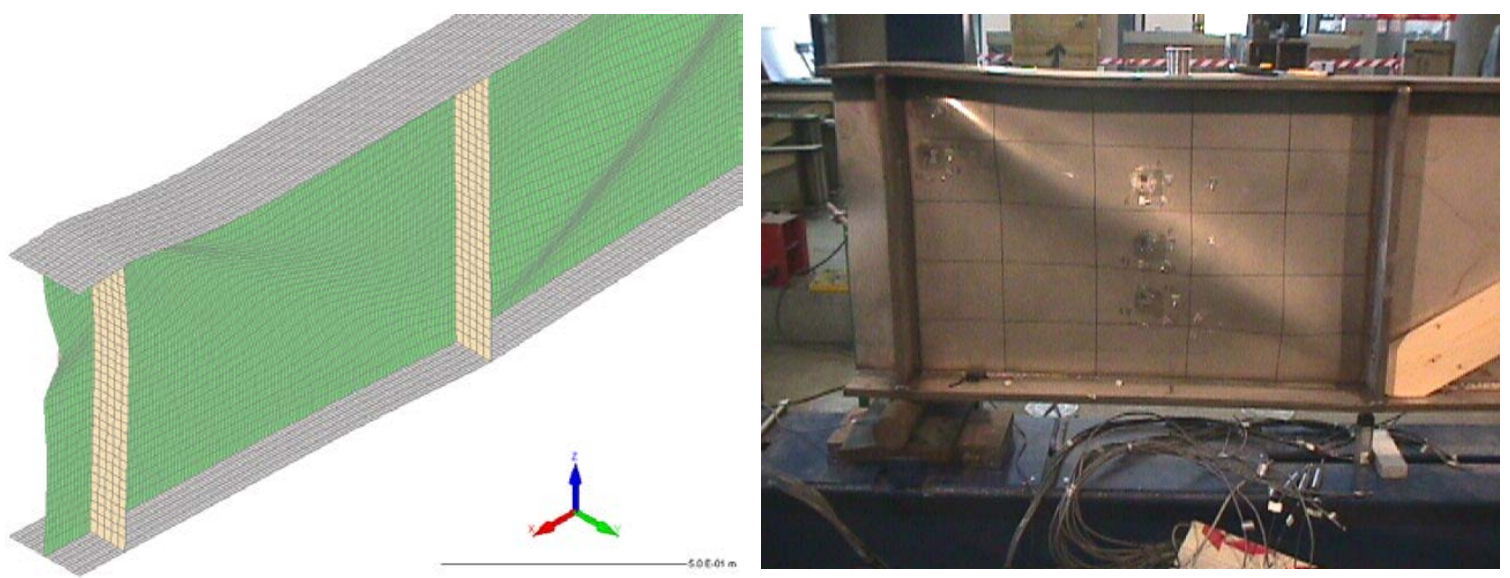

Figure 12 - PG5 numerical and experimental [11] deformed shape after test
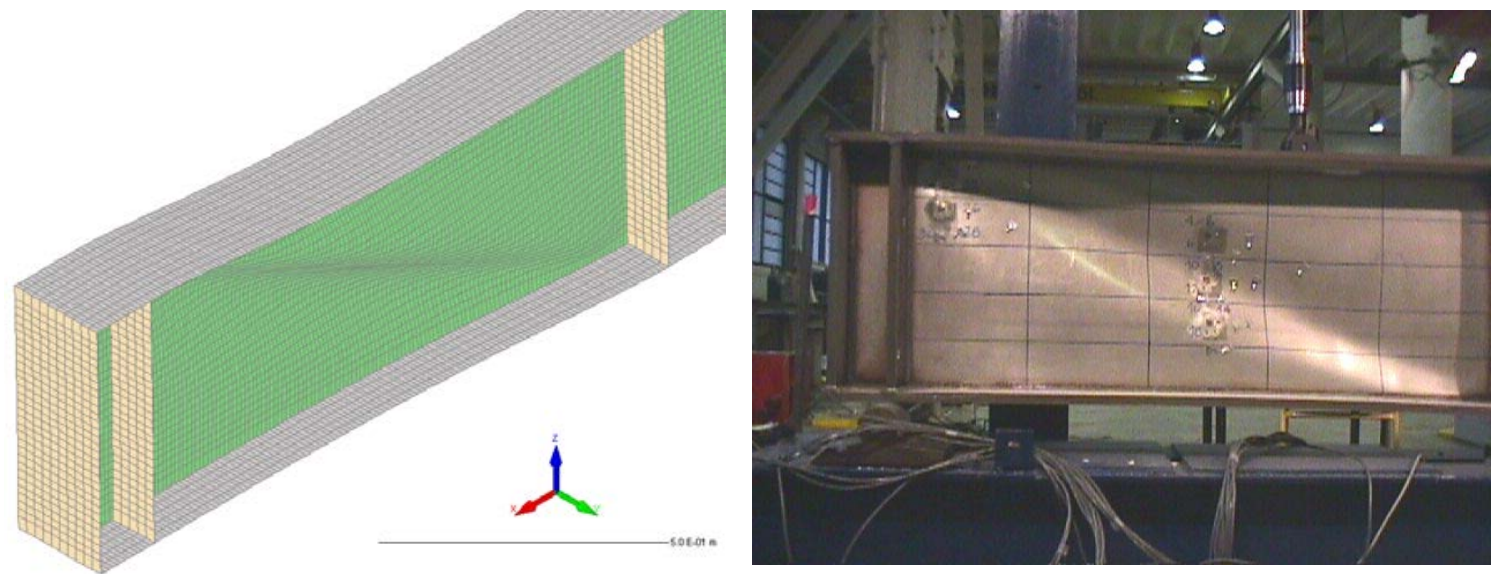

Figure 13 - PG10 numerical and experimental [11] deformed shape after test
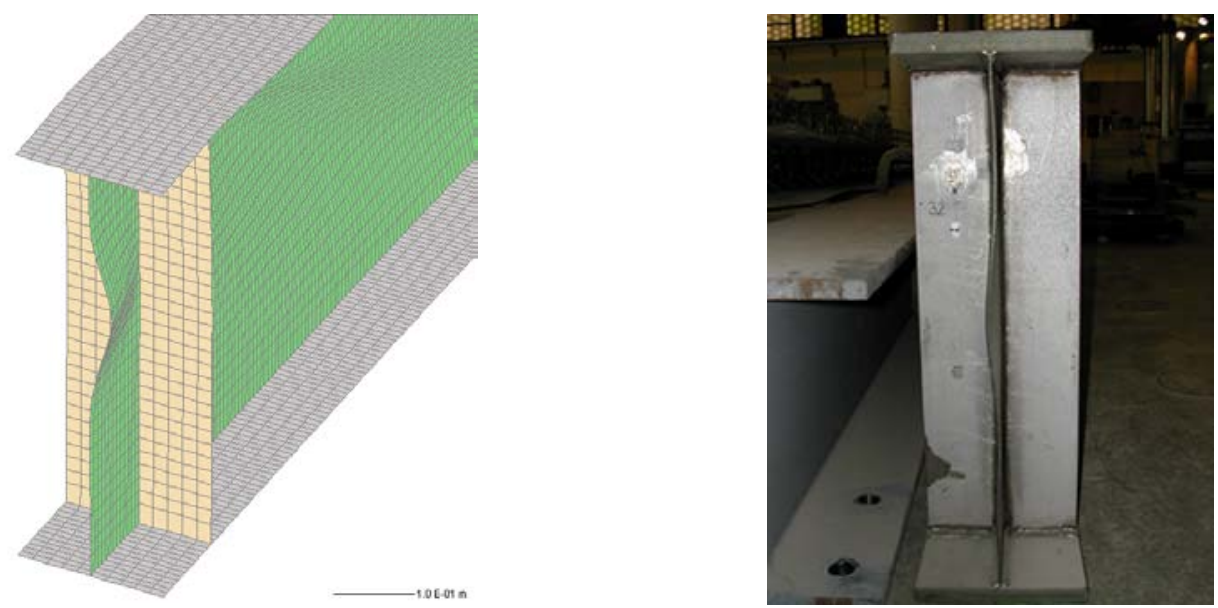

Figure 14 - Numerical and experimental [10] out of plane web buckling in the non-rigid end post of PG7 

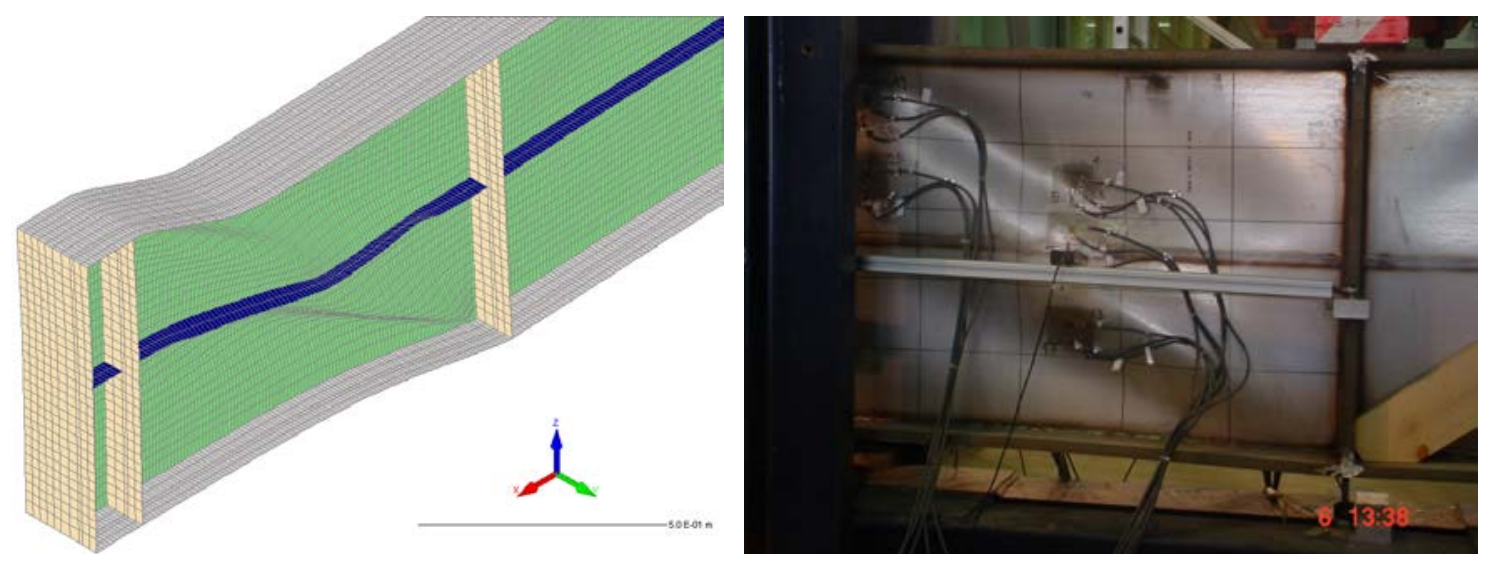

Figure 15 - PG17 numerical and experimental [10] deformed shape after test
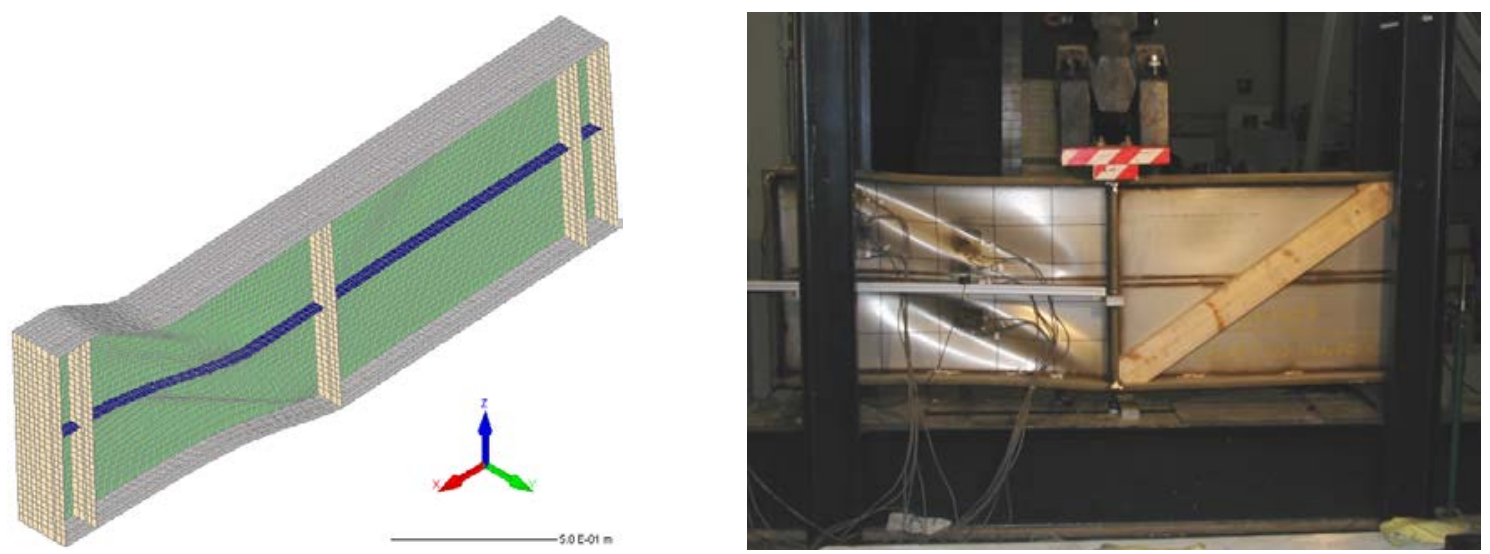

Figure 16 - PG19 numerical and experimental [10] deformed shape after test

A total of nine plate girders were tested at Imperial College London. These experimental tests were also numerically modelled [12] using the ABAQUS software. The ultimate load obtained with SAFIR is compared with both experimental and numerical results (see Table 7). The ultimate load values obtained from SAFIR numerical model showed good agreement with those obtained from the experimental tests. The mean deviation is equal to $3.8 \%$, a little more than the $2.6 \%$ mean deviation observed between ABAQUS and the experimental tests. 
Table 7 - Ultimate load of the plate girders tested at Imperial College London

\begin{tabular}{|l|ccc|cc|}
\hline \multirow{2}{*}{ Label } & \multicolumn{3}{|c|}{ Ultimate load [kN] } & \multicolumn{2}{c|}{ Deviation [\%] } \\
& Exp. Tests (1) & ABAQUS (2) & SAFIR (3) & (2) vs (1) & (3) vs (1) \\
\hline PG20 & 1124.0 & 1192.0 & 1072.4 & 6.0 & -4.6 \\
PG21 & 1776.0 & 1786.0 & 1764.5 & 0.6 & -0.6 \\
PG22 & 2652.0 & 2672.0 & 2814.3 & 0.8 & 6.1 \\
PG23 & 3676.0 & 3506.0 & 3781.4 & -4.6 & 2.9 \\
PG24 & 792.0 & 812.0 & 763.7 & 2.5 & -3.6 \\
PG25 & 1364.0 & 1400.0 & 1367.1 & 2.6 & 0.2 \\
PG26 & 1952.0 & 1908.0 & 2037.0 & -2.3 & 4.4 \\
PG27 & 2324.0 & 2304.0 & 2421.5 & -0.9 & 4.2 \\
PG28 & 3602.0 & 3494.0 & 3332.0 & -3.0 & -7.5 \\
\hline
\end{tabular}

In this experimental campaign at Imperial College London three different failure modes were observed. A shear dominant failure characterized by the web shear buckling is shown in Figure 17, whereas a bending dominant failure with local buckling of the plate girder upper flange can be seen in Figure 18. Finally, Figure 19 illustrates a failure mode involving an interaction between shear and bending, where both flange and web buckling may be observed. The deformed shapes obtained experimental and numerically are quite similar. Thus, it can be said that the numerical model developed in SAFIR was shown able to accurately reproduce different types of failures in plate girders subjected to shear.
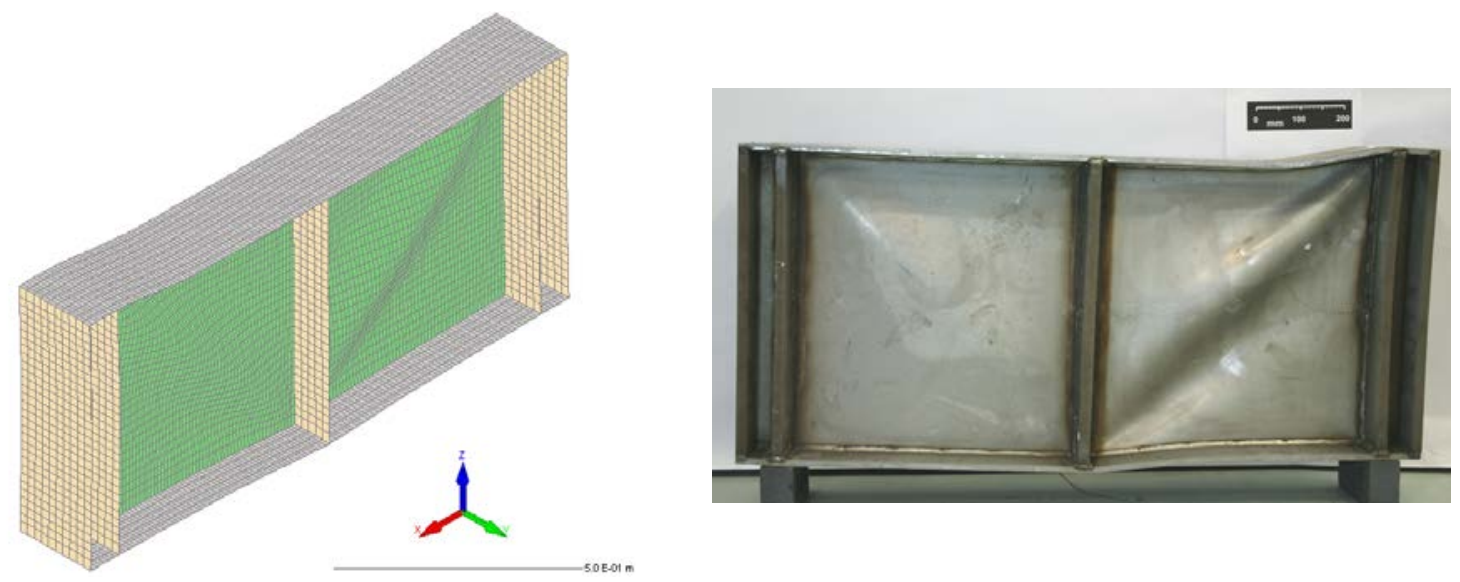

Figure 17 - PG20 numerical and experimental [12] deformed shape after test 

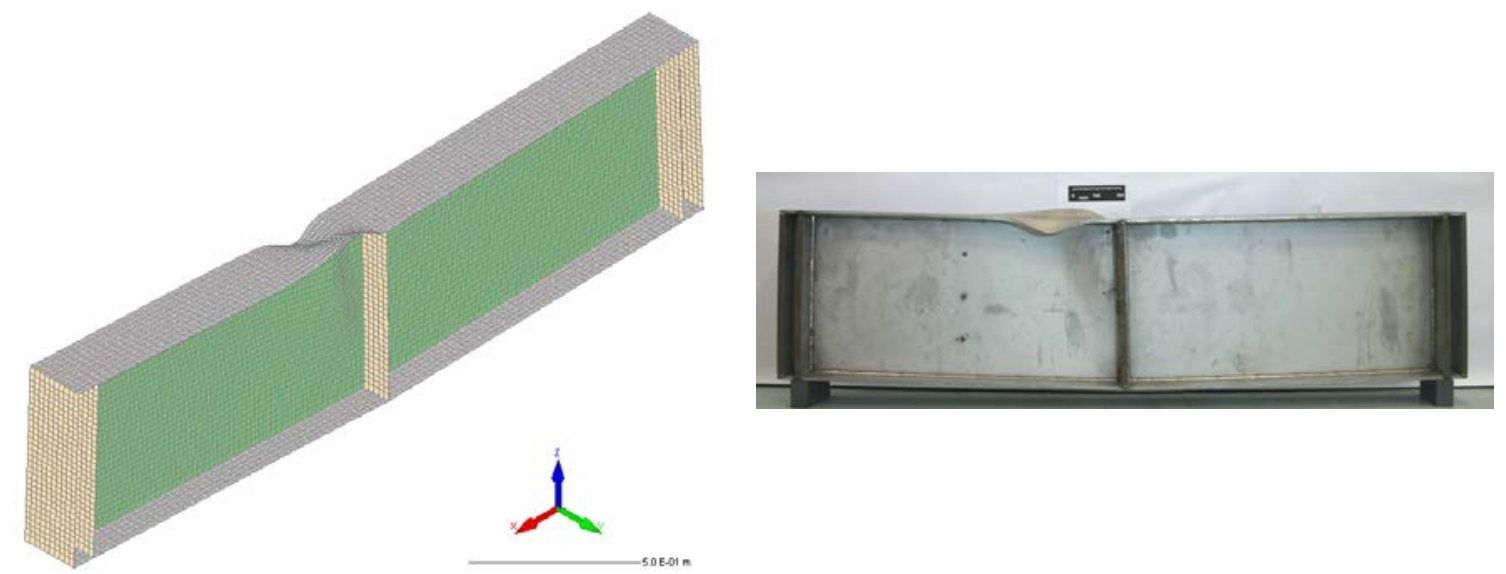

Figure 18 - PG27 numerical and experimental [12] deformed shape after test
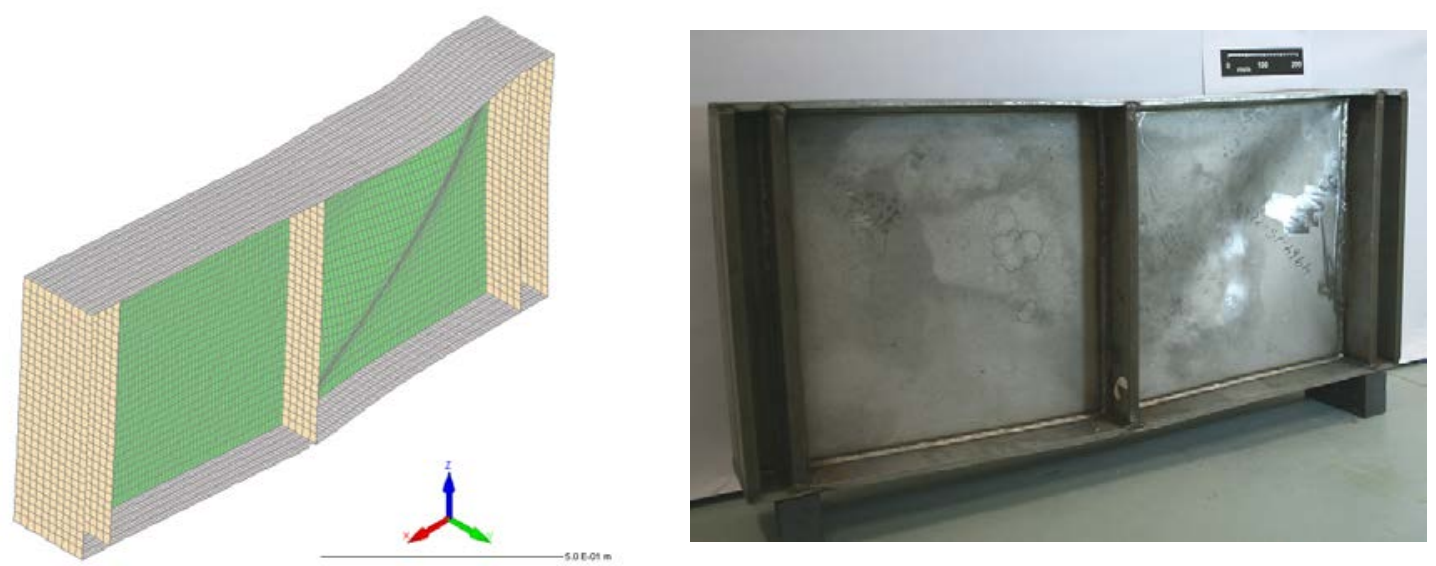

Figure 19 - PG22 numerical and experimental [12] deformed shape after test

The experimental tests carried out at Lulea University were numerically modelled by Olsson [3] using the ABAQUS software. A comparison between the numerical results obtained from SAFIR and ABAQUS and the experimental results was performed. As it can be seen in Table 8 , there is a very good agreement between the results of the experimental tests and the results provided by SAFIR, with a mean deviation equal to 2.5\%. In this case, the numerical model developed in SAFIR provided closer results than the numerical model developed in ABAQUS by Olsson, which has a $4.8 \%$ mean deviation. Figure 20 shows the deformed shape of the PG33 after the numerical and experimental tests, where it is possible to observe the same failure mode obtained in both tests. 
Table 8 - Ultimate load of plate girders tested at Lulea University of Technology

\begin{tabular}{|l|ccc|cc|}
\hline \multirow{2}{*}{ Label } & \multicolumn{3}{|c|}{ Ultimate load [kN] } & \multicolumn{2}{c|}{ Deviation [\%] } \\
& Exp. Tests (1) & ABAQUS (2) & SAFIR (3) & (2) vs (1) & (3) vs (1) \\
\hline PG29 & 332.5 & 353.9 & 316.6 & 6.4 & -4.8 \\
PG30 & 376.8 & 392.5 & 377.9 & 4.2 & 0.3 \\
PG31 & 403.8 & 409.2 & 395.8 & 1.3 & -2.0 \\
PG32 & 515.4 & 550.4 & 530.6 & 6.8 & 3.0 \\
PG33 & 610.5 & 643.3 & 632.6 & 5.4 & 3.6 \\
PG34 & 646.7 & 676.5 & 655.7 & 4.6 & 1.4 \\
\hline
\end{tabular}
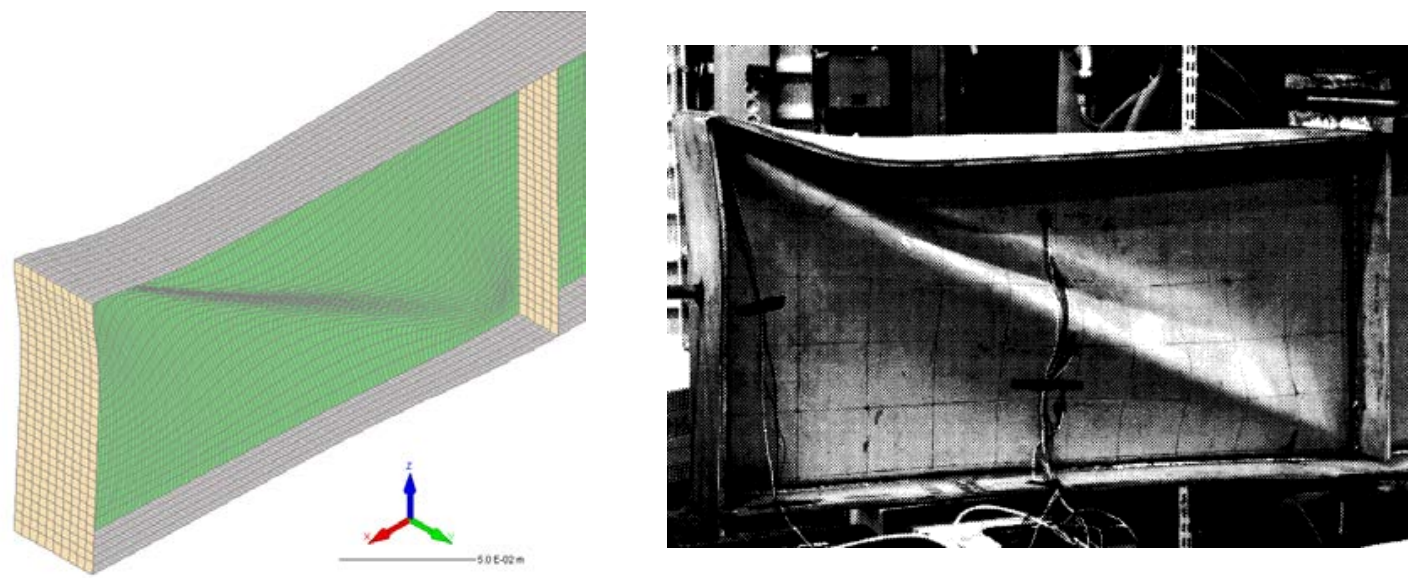

Figure 20 - PG33 numerical and experimental [3] deformed shape after test

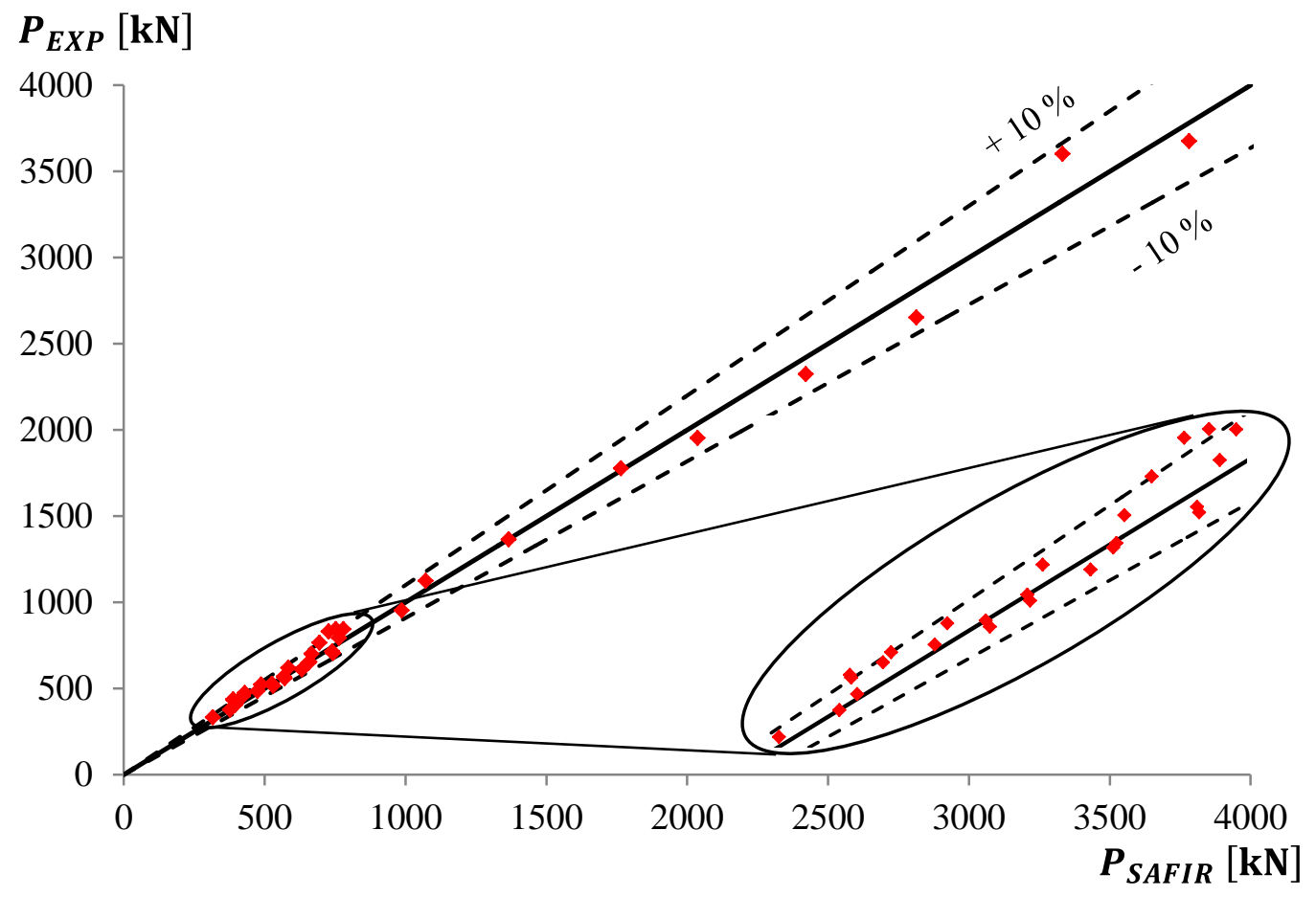

Figure 21 shows the comparison between the experimental and numerical ultimate shear 
strength for all the analysed stainless steel plate girders. As it can be seen, the results agree well with differences usually lower than $10 \%$. Despite the difference between the stress-strain curves observed in Figure 10 a) for the stainless syeel grade 1.4301, it can be concluded that the results presented in this paper regarding shear buckling in stainless steel plate girders are very good. Therefore, it is considered that the model applied in the programme SAFIR is able to reproduce the behaviour of stainless steel plate girders affected by shear buckling at normal temperature. As the software has been widely validated at elevated temperatures [26,27], it is expected that it is also capable to accurately simulate the shear buckling behaviour of stainless steel plate girders subjected to elevated temperatures.

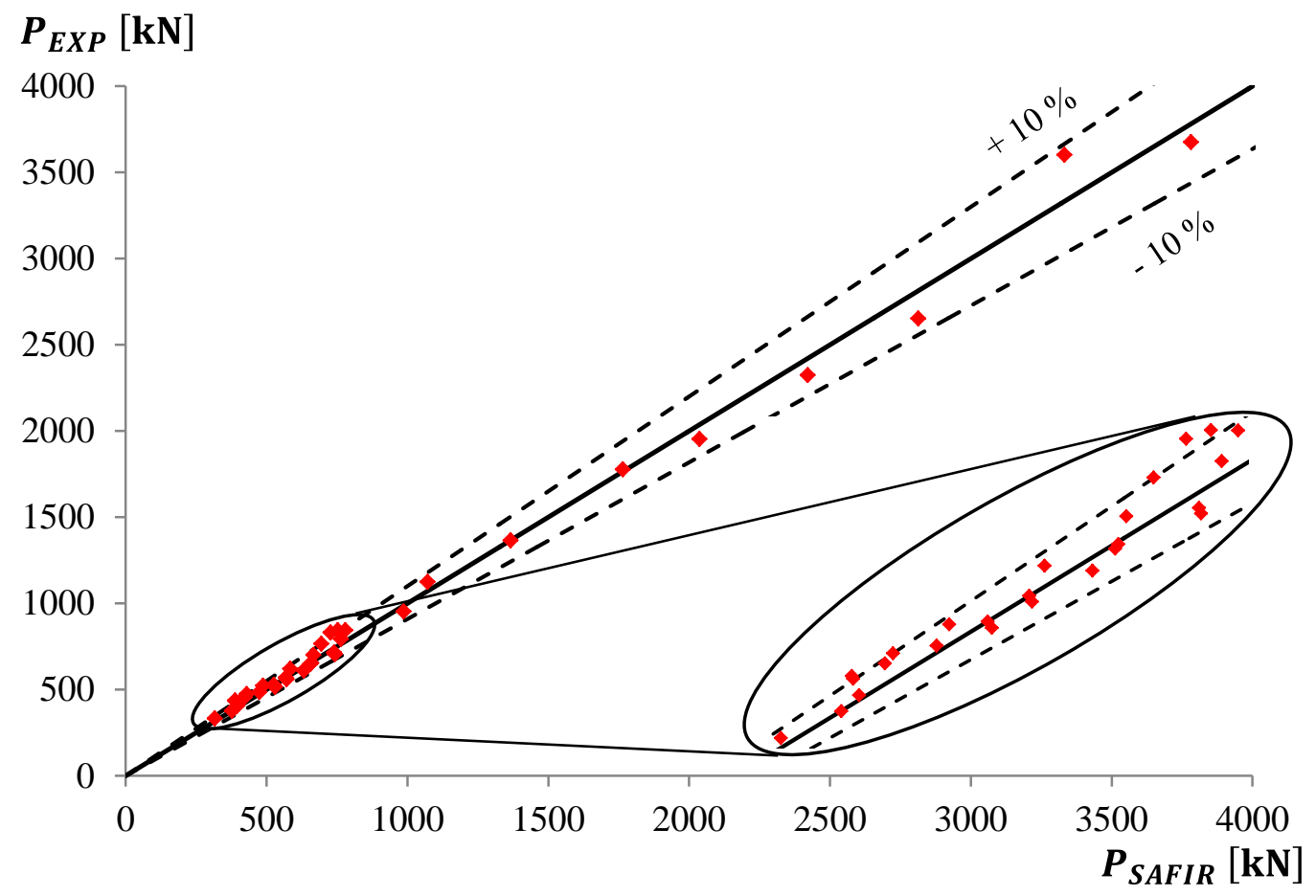

Figure 21 - Experimental and numerical ultimate shear strength 


\section{Influence of the initial imperfections on the ultimate shear strength of plate girders}

In this section, sensitivity analyses on the influence of the geometric imperfections and the residual stresses on the ultimate shear strength of stainless steel plate girders, at both normal and elevated temperatures, are presented. These sensitivity analyses were performed using the numerical model developed in SAFIR. Different maximum imperfection amplitudes were considered based on the web thickness, as well as the maximum amplitude recommended in EC3 and half of it. Part 1-5 of EC3 [9] recommends the use of geometric imperfections with a maximum amplitude equal to $80 \%$ of the essential manufacturing tolerances, which can be found in EN 1090-2 [28]. This way, a maximum amplitude equal to $0.8 \mathrm{~h}_{\mathrm{w}} / 100$ in the web and $0.8 \mathrm{~b}_{\mathrm{f}} / 100$ in the flanges was used.

Regarding residual stresses, the authors of the experimental tests did not take them into account in the numerical modelling. Therefore, the residual stresses were also not taken into account in the numerical modelling presented in section 4 of this work. However, in this section their influence in the ultimate shear strength of stainless steel plate girders is evaluated. The pattern of residual stresses considered was the one proposed for welded I-sections, as shown in Figure 22 [29, 30]. 


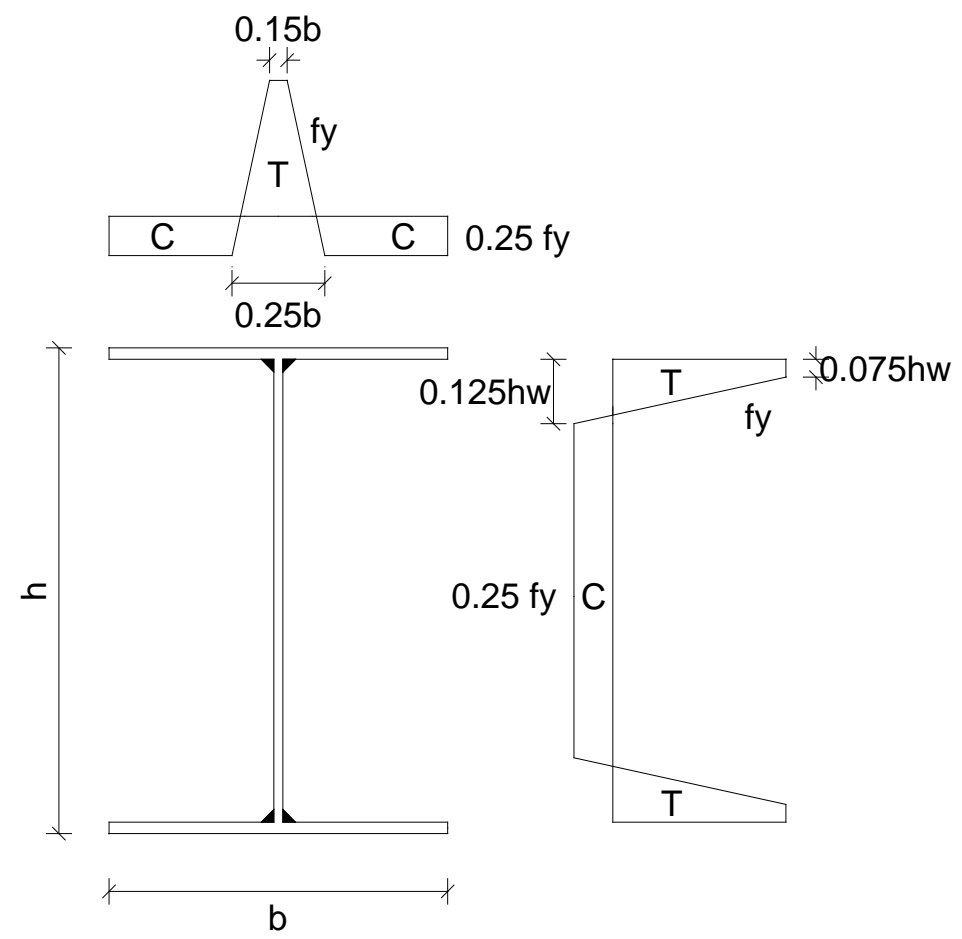

Figure 22 - Pattern of residual stresses for welded I-sections

The sensitivity analyses presented in this section were performed based on the stainless steel plate girders tested at Polytechnic University of Catalunya whose dimensions and material properties were already presented in section 2 of this work. The sensitivity analyses at elevated temperature are performed using the same plate girders analysed at normal temperature. In this case, the plate girders are subjected to a uniform temperature equal to $500^{\circ} \mathrm{C}$ under steady-state conditions, i.e., the temperature is considered constant while the load is increased.

\subsection{Normal temperature}

The consideration of the geometric imperfections on the numerical modelling of stainless steel plate girders is very important. In this initial sensitivity analysis of the geometric imperfections, a wide range of maximum amplitudes of the geometric imperfections was considered at normal temperature. The results are presented in Table 
9, where it can be observed that the lower the maximum amplitude of the geometric imperfections is, the lower the differences between the numerical and the experimental results are. This geometric imperfections sensitivity analysis also showed that for plate girders with aspect ratio $\left(\mathrm{a} / \mathrm{h}_{\mathrm{w}}\right)$ lower than 2.5 , the influence of the maximum amplitude of the geometric imperfections in the ultimate load of the analyzed plate girders is quite low. On the other hand, for plate girders with aspect ratio equal or larger than 2.5, it is possible to note that the higher the maximum amplitude of the geometric imperfections is, the lower the ultimate shear strength is.

Bearing in mind the influence of the residual stresses on the ultimate shear strength of stainless steel plate girders, numerical analysis taken into account residual stresses and considering two different maximum amplitudes were performed. The comparison between the results with and without residual stresses is presented in Table 10, where one can observe that there is no substantial influence of the residual stresses on the ultimate shear strength of stainless steel plate girders at normal temperature. 
Table 9 - Ultimate loads for different maximum amplitudes of the geometric imperfections at normal temperature

\begin{tabular}{|c|c|c|c|c|c|c|c|c|c|c|c|c|c|c|c|c|c|c|c|c|}
\hline \multirow{2}{*}{\multicolumn{3}{|c|}{ Experimental Test }} & \multicolumn{18}{|c|}{ Maximum amplitude of geometric imperfections } \\
\hline & & & \multicolumn{2}{|c|}{$\mathrm{tw} / 1000$} & \multicolumn{2}{|c|}{$\mathrm{tw} / 100$} & \multicolumn{2}{|c|}{$\mathrm{tw} / 20$} & \multicolumn{2}{|c|}{$\mathrm{tw} / 10$} & \multicolumn{2}{|c|}{$\mathrm{tw} / 5$} & \multicolumn{2}{|c|}{$\mathrm{tw} / 2$} & \multicolumn{2}{|c|}{$\mathrm{tw}$} & \multicolumn{2}{|c|}{$0.5 \mathrm{EC} 3$} & \multicolumn{2}{|c|}{ EC3 } \\
\hline Designation & $\mathrm{a} / \mathrm{h}_{\mathrm{w}}$ & $\mathrm{P}[\mathrm{kN}]$ & $\begin{array}{c}\mathrm{P} \\
{[\mathrm{kN}]}\end{array}$ & $\begin{array}{l}\text { Dev. } \\
{[\%]}\end{array}$ & $\begin{array}{c}\mathrm{P} \\
{[\mathrm{kN}]}\end{array}$ & $\begin{array}{l}\text { Dev. } \\
{[\%]}\end{array}$ & $\begin{array}{c}\mathrm{P} \\
{[\mathrm{kN}]}\end{array}$ & $\begin{array}{l}\text { Dev. } \\
\text { [\%] }\end{array}$ & $\begin{array}{c}\mathrm{P} \\
{[\mathrm{kN}]}\end{array}$ & $\begin{array}{c}\text { Dev. } \\
\text { [\%] }\end{array}$ & $\begin{array}{c}\mathrm{P} \\
{[\mathrm{kN}]}\end{array}$ & $\begin{array}{l}\text { Dev. } \\
\text { [\%] }\end{array}$ & $\begin{array}{c}\mathrm{P} \\
{[\mathrm{kN}]}\end{array}$ & $\begin{array}{l}\text { Dev. } \\
\text { [\%] }\end{array}$ & $\begin{array}{c}\mathrm{P} \\
{[\mathrm{kN}]}\end{array}$ & $\begin{array}{l}\text { Dev. } \\
\text { [\%] }\end{array}$ & $\begin{array}{c}\mathrm{P} \\
{[\mathrm{kN}]}\end{array}$ & $\begin{array}{c}\text { Dev. } \\
\text { [\%] }\end{array}$ & $\begin{array}{c}\mathrm{P} \\
{[\mathrm{kN}]}\end{array}$ & $\begin{array}{l}\text { Dev. } \\
{[\%]}\end{array}$ \\
\hline PG1 & 0.50 & 952.6 & 986.4 & 3.5 & 986.3 & 3.5 & 986.2 & 3.5 & 986.4 & 3.5 & 986.4 & 3.5 & 986.9 & 3.6 & 992.5 & 4.2 & 992.5 & 4.2 & 993.8 & 4.3 \\
\hline PG2 & 1.00 & 705.0 & 742.8 & 5.4 & 742.9 & 5.4 & 742.9 & 5.4 & 742.8 & 5.4 & 742.8 & 5.4 & 742.8 & 5.4 & 742.7 & 5.3 & 742.8 & 5.4 & 742.7 & 5.3 \\
\hline PG3 & 1.50 & 568.8 & 568.3 & -0.1 & 568.4 & -0.1 & 568.4 & -0.1 & 568.4 & -0.1 & 568.3 & -0.1 & 568.3 & -0.1 & 568.4 & -0.1 & 568.4 & -0.1 & 568.4 & -0.1 \\
\hline PG4 & 2.00 & 485.8 & 474.9 & -2.3 & 474.9 & -2.2 & 474.6 & -2.3 & 474.5 & -2.3 & 474.4 & -2.3 & 474.3 & -2.4 & 473.9 & -2.5 & 474.3 & -2.4 & 473.9 & -2.5 \\
\hline PG5 & 1.50 & 618.4 & 584.0 & -5.6 & 584.0 & -5.6 & 584.0 & -5.6 & 584.0 & -5.6 & 584.0 & -5.6 & 584.0 & -5.6 & 584.1 & -5.6 & 584.0 & -5.6 & 584.1 & -5.5 \\
\hline PG6 & 1.50 & 654.3 & 658.9 & 0.7 & 658.9 & 0.7 & 658.9 & 0.7 & 658.9 & 0.7 & 658.8 & 0.7 & 658.8 & 0.7 & 658.7 & 0.7 & 658.8 & 0.7 & 658.7 & 0.7 \\
\hline PG7 & 2.00 & 521.3 & 483.9 & -7.2 & 487.2 & -6.5 & 486.0 & -6.8 & 487.3 & -6.5 & 484.7 & -7.0 & 487.4 & -6.5 & 487.3 & -6.5 & 487.4 & -6.5 & 487.4 & -6.5 \\
\hline PG8 & 2.00 & 525.8 & 526.8 & 0.2 & 526.7 & 0.2 & 526.5 & 0.1 & 526.3 & 0.1 & 526.2 & 0.1 & 525.9 & 0.0 & 525.4 & -0.1 & 525.8 & 0.0 & 525.2 & -0.1 \\
\hline PG9 & 2.50 & 456.1 & 425.6 & -6.7 & 424.8 & -6.9 & 423.1 & -7.2 & 421.9 & -7.5 & 420.3 & -7.8 & 418.6 & -8.2 & 417.2 & -8.5 & 418.6 & -8.2 & 417.2 & -8.5 \\
\hline PG10 & 2.50 & 473.1 & 429.0 & -9.3 & 428.4 & -9.5 & 426.8 & -9.8 & 430.2 & -9.1 & 430.1 & -9.1 & 431.2 & -8.9 & 431.1 & -8.9 & 431.2 & -8.9 & 431.1 & -8.9 \\
\hline PG11 & 3.25 & 435.8 & 405.6 & -6.9 & 400.1 & -8.2 & 392.7 & -9.9 & 388.5 & -10.9 & 383.1 & -12.1 & 374.2 & -14.1 & 365.3 & -16.2 & 376.6 & -13.6 & 368.3 & -15.5 \\
\hline PG12 & 3.25 & 430.7 & 406.4 & -5.6 & 401.0 & -6.9 & 393.8 & -8.6 & 389.8 & -9.5 & 384.6 & -10.7 & 375.6 & -12.8 & 366.9 & -14.8 & 377.9 & -12.2 & 369.7 & -14.2 \\
\hline PG13 & 1.00 & 714.7 & 740.7 & 3.6 & 740.8 & 3.7 & 741.2 & 3.7 & 740.8 & 3.7 & 741.2 & 3.7 & 741.0 & 3.7 & 740.9 & 3.7 & 741.0 & 3.7 & 740.9 & 3.7 \\
\hline PG14 & 1.50 & 558.9 & 571.9 & 2.3 & 571.8 & 2.3 & 571.6 & 2.3 & 571.4 & 2.2 & 571.2 & 2.2 & 570.9 & 2.1 & 570.5 & 2.1 & 570.9 & 2.1 & 570.5 & 2.1 \\
\hline PG15 & 1.50 & 700.7 & 671.2 & -4.2 & 667.0 & -4.8 & 667.1 & -4.8 & 667.1 & -4.8 & 667.0 & -4.8 & 666.9 & -4.8 & 667.1 & -4.8 & 666.9 & -4.8 & 667.1 & -4.8 \\
\hline PG16 & 1.50 & 764.7 & 729.5 & -4.6 & 718.9 & -6.0 & 703.6 & -8.0 & 694.4 & -9.2 & 690.3 & -9.7 & 691.5 & -9.6 & 664.0 & -13.2 & 660.4 & -13.6 & 688.2 & -10.0 \\
\hline PG17 & 1.50 & 829.0 & 756.8 & -8.7 & 747.0 & -9.9 & 734.7 & -11.4 & 727.5 & -12.2 & 718.9 & -13.3 & 704.7 & -15.0 & 702.2 & -15.3 & 698.1 & -15.8 & 701.8 & -15.3 \\
\hline PG18 & 1.50 & 843.7 & 782.3 & -7.3 & 772.2 & -8.5 & 759.7 & -9.9 & 752.7 & -10.8 & 744.4 & -11.8 & 730.4 & -13.4 & 717.1 & -15.0 & 724.3 & -14.2 & 725.2 & -14.0 \\
\hline PG19 & 1.50 & 843.1 & 809.9 & -3.9 & 799.6 & -5.2 & 787.0 & -6.6 & 780.5 & -7.4 & 770.0 & -8.7 & 753.6 & -10.6 & 735.6 & -12.8 & 745.5 & -11.6 & 723.5 & -14.2 \\
\hline \multicolumn{3}{|c|}{ Mean deviation [\%] } & & -3.0 & & -3.4 & & -4.0 & & -4.2 & & -4.6 & & -5.1 & & -5.7 & & -5.3 & & -5.5 \\
\hline
\end{tabular}


Table 10 - Residual stresses sensitivity analysis at normal temperature

\begin{tabular}{|c|c|c|c|c|c|c|c|}
\hline \multirow{3}{*}{ Designation } & \multirow{3}{*}{$\mathrm{a} / \mathrm{h}_{\mathrm{w}}$} & \multicolumn{2}{|c|}{ With Imperfections } & \multicolumn{4}{|c|}{ With Imperfections + Residual Stresses } \\
\hline & & $\mathrm{tw} / 10 \mathrm{Imp}$ & EC3 Imp. & \multicolumn{2}{|c|}{ tw/10 Imp. } & \multicolumn{2}{|c|}{ EC3 Imp. } \\
\hline & & $\mathrm{P}[\mathrm{kN}]$ & $\mathrm{P}[\mathrm{kN}]$ & $\mathrm{P}[\mathrm{kN}]$ & Dev. [\%] & $\mathrm{P}[\mathrm{kN}]$ & Dev. [\%] \\
\hline PG1 & 0.50 & 986.4 & 993.8 & 988.2 & 0.2 & 994.4 & 0.1 \\
\hline PG2 & 1.00 & 742.8 & 742.7 & 742.2 & -0.1 & 742.3 & -0.1 \\
\hline PG3 & 1.50 & 568.4 & 568.4 & 568.5 & 0.0 & 568.4 & 0.0 \\
\hline PG4 & 2.00 & 474.5 & 473.9 & 474.9 & 0.1 & 473.7 & 0.0 \\
\hline PG5 & 1.50 & 584.0 & 584.1 & 585.3 & 0.2 & 584.9 & 0.1 \\
\hline PG6 & 1.50 & 658.9 & 658.7 & 660.6 & 0.3 & 659.3 & 0.1 \\
\hline PG7 & 2.00 & 487.3 & 487.4 & 487.7 & 0.1 & 487.8 & 0.1 \\
\hline PG8 & 2.00 & 526.3 & 525.2 & 527.1 & 0.2 & 525.7 & 0.1 \\
\hline PG9 & 2.50 & 421.9 & 417.2 & 418.9 & -0.7 & 414.2 & -0.7 \\
\hline PG10 & 2.50 & 430.2 & 431.1 & 432.2 & 0.5 & 429.4 & -0.4 \\
\hline PG11 & 3.25 & 388.5 & 368.3 & 376.9 & -3.0 & 364.0 & -1.2 \\
\hline PG12 & 3.25 & 389.8 & 369.7 & 377.8 & -3.1 & 365.6 & -1.1 \\
\hline PG13 & 1.00 & 740.8 & 740.9 & 741.2 & 0.1 & 741.1 & 0.0 \\
\hline PG14 & 1.50 & 571.4 & 570.5 & 571.9 & 0.1 & 570.9 & 0.1 \\
\hline PG15 & 1.50 & 667.1 & 667.1 & 664.3 & -0.4 & 667.4 & 0.1 \\
\hline PG16 & 1.50 & 694.4 & 688.2 & 691.0 & -0.5 & 688.5 & 0.0 \\
\hline PG17 & 1.50 & 727.5 & 701.8 & 697.8 & -4.1 & 701.8 & 0.0 \\
\hline PG18 & 1.50 & 752.7 & 725.2 & 726.4 & -3.5 & 720.3 & -0.7 \\
\hline PG19 & 1.50 & 780.5 & 723.5 & 741.3 & -5.0 & 730.6 & 1.0 \\
\hline \multicolumn{4}{|c|}{ Mean deviation [\%] } & & -1.0 & & -0.1 \\
\hline
\end{tabular}

\subsection{Elevated temperature}

Table 11 shows the geometric imperfections sensitivity analysis performed in stainless steel plate girders subjected to elevated temperatures. As at normal temperature, at $500^{\circ} \mathrm{C}$ the geometric imperfections have no substantial influence on the ultimate shear strength of stainless steel plate girders with aspect ratio lower than 2.5. For plate girders with aspect ratio equal or larger than 2.5, it was observed that the higher the maximum amplitude of the geometric imperfections is, the lower the ultimate shear strength is.

Regarding residual stresses, its influence on the ultimate shear strength is higher at elevated temperatures than at normal temperature, as one can observe in Table 12. On the one hand, it was shown that the higher the amplitude of the geometric imperfections 
is, the higher the influence of the residual stresses is. On the other hand, the results presented in Table 12 show that the influence of the residual stresses on the ultimate shear capacity of plate girders subjected to $500^{\circ} \mathrm{C}$ is lower for plate girders with aspect ratios up to 1.5. Nevertheless, it is important to note that the residual stresses influence is on average $1.6 \%$, which may be considered as no significant influence.

Table 11 - Geometric imperfections sensitivity analysis at elevated temperature

\begin{tabular}{|c|c|cc|c|}
\hline Designation & $\mathrm{a} / \mathrm{h}_{\mathrm{w}}$ & $\begin{array}{c}\text { tw/10 Imp. } \\
\mathrm{P}[\mathrm{kN}]\end{array}$ & $\begin{array}{c}\text { EC3 Imp. } \\
\mathrm{P}[\mathrm{kN}]\end{array}$ & $\begin{array}{c}\text { Deviation } \\
{[\%]}\end{array}$ \\
\hline PG1 & 0.50 & 554.1 & 565.8 & 2.1 \\
PG2 & 1.00 & 444.8 & 445.4 & 0.1 \\
PG3 & 1.50 & 327.8 & 327.8 & 0.0 \\
PG4 & 2.00 & 262.4 & 267.1 & 1.8 \\
PG5 & 1.50 & 330.2 & 329.8 & -0.1 \\
PG6 & 1.50 & 369.6 & 369.3 & -0.1 \\
PG7 & 2.00 & 277.4 & 270.7 & -2.4 \\
PG8 & 2.00 & 290.5 & 291.2 & 0.2 \\
PG9 & 2.50 & 253.6 & 235.2 & -7.3 \\
PG10 & 2.50 & 255.3 & 237.9 & -6.8 \\
PG11 & 3.25 & 234.9 & 210.7 & -10.3 \\
PG12 & 3.25 & 235.6 & 211.5 & -10.2 \\
PG13 & 1.00 & 431.1 & 429.5 & -0.4 \\
PG14 & 1.50 & 318.6 & 318.4 & -0.1 \\
PG15 & 1.50 & 377.4 & 375.2 & -0.6 \\
PG16 & 1.50 & 430.4 & 387.9 & -9.9 \\
PG17 & 1.50 & 439.3 & 390.2 & -11.2 \\
PG18 & 1.50 & 445.7 & 410.7 & -7.9 \\
PG19 & 1.50 & 449.7 & 419.7 & -6.7 \\
\hline & & Mean deviation [\%] & -3.7 \\
\hline
\end{tabular}


Table 12 - Residual stresses sensitivity analysis at elevated temperature

\begin{tabular}{|c|c|c|c|c|c|c|c|}
\hline \multirow{3}{*}{ Designation } & \multirow{3}{*}{$\mathrm{a} / \mathrm{hw}$} & \multicolumn{2}{|c|}{ With Imperfections } & \multicolumn{4}{|c|}{ With Imperfections + Residual Stresses } \\
\hline & & tw/10 Imp. & EC3 Imp. & \multicolumn{2}{|c|}{ tw/10 Imp. } & \multicolumn{2}{|c|}{ EC3 Imp. } \\
\hline & & $\mathrm{P}[\mathrm{kN}]$ & $\mathrm{P}[\mathrm{kN}]$ & $\mathrm{P}[\mathrm{kN}]$ & Dev. [\%] & $\mathrm{P}[\mathrm{kN}]$ & Dev. [\%] \\
\hline PG1 & 0.5 & 554.1 & 565.8 & 555.3 & 0.2 & 566.3 & 0.1 \\
\hline PG2 & 1.0 & 444.8 & 445.4 & 445.4 & 0.1 & 445.5 & 0.0 \\
\hline PG3 & 1.5 & 327.8 & 327.8 & 328.0 & 0.1 & 327.9 & 0.0 \\
\hline PG4 & 2.0 & 262.4 & 267.1 & 267.6 & 2.0 & 267.5 & 0.1 \\
\hline PG5 & 1.5 & 330.2 & 329.8 & 330.3 & 0.0 & 330.1 & 0.1 \\
\hline PG6 & 1.5 & 369.6 & 369.3 & 370.5 & 0.2 & 370.2 & 0.3 \\
\hline PG7 & 2.0 & 277.4 & 270.7 & 271.3 & -2.2 & 267.2 & -1.3 \\
\hline PG8 & 2.0 & 290.5 & 291.2 & 288.7 & -0.6 & 291.9 & 0.2 \\
\hline PG9 & 2.5 & 253.6 & 235.2 & 242.0 & -4.6 & 231.2 & -1.7 \\
\hline PG10 & 2.5 & 255.3 & 237.9 & 243.4 & -4.7 & 238.7 & 0.4 \\
\hline PG11 & 3.3 & 234.9 & 210.7 & 224.4 & -4.5 & 207.1 & -1.7 \\
\hline PG12 & 3.3 & 235.6 & 211.5 & 225.0 & -4.5 & 207.6 & -1.8 \\
\hline PG13 & 1.0 & 431.1 & 429.5 & 430.6 & -0.1 & 429.6 & 0.0 \\
\hline PG14 & 1.5 & 318.6 & 318.4 & 319.0 & 0.1 & 318.2 & -0.1 \\
\hline PG15 & 1.5 & 377.4 & 375.2 & 376.3 & -0.3 & 375.4 & 0.1 \\
\hline PG16 & 1.5 & 430.4 & 387.9 & 412.7 & -4.1 & 388.2 & 0.1 \\
\hline PG17 & 1.5 & 439.3 & 390.2 & 422.1 & -3.9 & 395.7 & 1.4 \\
\hline PG18 & 1.5 & 445.7 & 410.7 & 436.3 & -2.1 & 403.4 & -1.8 \\
\hline PG19 & 1.5 & 449.7 & 419.7 & 443.7 & -1.4 & 411.4 & -2.0 \\
\hline \multicolumn{4}{|c|}{ Mean deviation [\%] } & & -1.6 & & -0.4 \\
\hline
\end{tabular}

\section{Comparison of numerical results with analytical expressions}

\subsection{EC3 design rules}

The ultimate shear strength of plate structural elements subjected to shear buckling must be checked according to Part 1-5 of EC3 [31]. For plate structural elements made of stainless steel some modifications are needed according to Part 1-4 of EC3 [5].

\subsubsection{Design at normal temperature}

The shear buckling resistance of stainless steel plate girders must be assessed when $h_{w} / t_{w}>52 \varepsilon / \eta$ for unstiffened webs and $h_{w} / t_{w}>23 \varepsilon / \eta \sqrt{k_{\tau}}$ for stiffened webs, where $h_{w}$ is the web height, $t_{w}$ is the web thickness, $\varepsilon$ is a parameter that depends on 
the steel yield strength and on the Young's modulus, $\eta$ is a coefficient related to the strain hardening and $k_{\tau}$ is the shear buckling coefficient of the web plate. If these conditions are fulfil it is still necessary to provide transverse stiffeners at the supports.

The Rotated Stress Field Method [4] is the basis of the shear design rules given in Section 5 of Part 1-5 of EC3 [31], where the shear design resistance is expressed as the sum of the web resistance to shear buckling and the flange contribution. Regarding stainless steel plate girders, Part 1-4 of EC3 [5] states some modifications to the design procedures of Part 1-5 of EC3. The differences appeared in the definition of the shear buckling reduction factor $\chi_{w}$ and in the calculation of the distance c. These two parameters must be obtained from clause 5.6(3) and 5.6(4) of Part 1-4 of EC3, respectively.

\subsubsection{Design in fire situation}

No specific rules for the shear buckling verification in case of fire are given in Part 1-2 of EC3 [16]. Owing to this absence of guidance, the use of the design rules at normal temperature, adapted to fire situation by the direct application of the reduction factors for the stress-strain relationship of steel at elevated temperatures, is a simple procedure that may be used to assess the shear buckling resistance at elevated temperatures. In this procedure, $k_{y, \theta}$ is applied to take into account the reduction of the steel yield strength caused by the elevated temperatures, whereas $k_{E, \theta}$ is used to reduce the Young's modulus in Eq. (2) [32], for the calculation of the parameter $\varepsilon_{\theta}$ needed for the calculation of the plate slenderness in fire situation. Finally, $k_{0.2 p, \theta}$ is used for Class 4 sections to consider the reduction of the bending resistance at elevated temperatures. These reduction factors are given in Part 1-2 of EC3. 


$$
\varepsilon_{\theta}=\sqrt{\frac{235}{k_{y, \theta} f_{y}}} \sqrt{\frac{k_{E, \theta} E}{210000}} \text { with } f_{y} \text { and } E \text { in }[\mathrm{MPa}]
$$

\subsection{Comparisons with numerical results}

The ultimate shear strength obtained in both experimental tests and numerical modelling are compared with the predictions according to the procedures presented above, included in Eurocode 3, Parts 1.2, 1.4 and 1.5 [5,16,31]. The numerical results used in this section were obtained considering geometric imperfections and residual stresses. The maximum amplitude of the geometric imperfections was the one presented in Section 5, as recommended in Annex C of Part 1-5 of Eurocode 3. The pattern of residual stresses considered was the one presented in Figure 22, typical of welded Isections.

\subsubsection{Normal temperature}

Table 13 summarizes the values of the ultimate shear effort at normal temperature. Apart from the agreement between the numerical and the experimental results, that was already discussed in detail in Section 4, the predictions given by the Eurocode 3 design procedures underestimate the shear buckling resistance of the analysed plate girders. For the nineteen analysed plate girders, the average $\mathrm{V}_{\operatorname{Exp}} / \mathrm{V}_{\text {EC3 }}$ ratio is 1.26 and the average $\mathrm{V}_{\mathrm{SAFIR}} / \mathrm{V}_{\mathrm{EC} 3}$ ratio is 1.18 . The standard deviation of the obtained result is 0.16 when comparing the analytical results with the experimental ones and 0.14 when comparing the analytical results with the numerical results. On the other hand, the difference between rigid and non-rigid end post is not taken into account in the current design procedures and, in both experimental and numerical tests, it was observed that in some cases the presence of a rigid end post may be an important increase of strength and it should be included in the design procedures. 
Table 13 - Ultimate shear strength at normal temperature

\begin{tabular}{|c|c|c|c|c|c|c|c|}
\hline Designation & $\mathrm{a} / \mathrm{h}_{\mathrm{w}}$ & $\begin{array}{c}\mathrm{V}_{\operatorname{Exp}}[\mathrm{kN}] \\
\text { (1) }\end{array}$ & $\begin{array}{c}\mathrm{V}_{\text {SAFIR }}[\mathrm{kN}] \\
(2)\end{array}$ & $\begin{array}{c}\mathrm{V}_{\mathrm{EC} 3}[\mathrm{kN}] \\
\text { (3) }\end{array}$ & $(1) /(2)$ & $\begin{array}{l}\text { Safety Factor } \\
\text { (1)/(3) }\end{array}$ & $(2) /(3)$ \\
\hline PG1 & 0.50 & 476.30 & 497.2 & 523.7 & 0.96 & 0.91 & 0.95 \\
\hline PG2 & 1.00 & 352.50 & 371.2 & 292.6 & 0.95 & 1.20 & 1.27 \\
\hline PG3 & 1.50 & 284.40 & 284.2 & 240.4 & 1.00 & 1.18 & 1.18 \\
\hline PG4 & 2.00 & 242.90 & 236.9 & 216.4 & 1.03 & 1.12 & 1.09 \\
\hline PG5 & 1.50 & 309.21 & 292.5 & 257.6 & 1.06 & 1.20 & 1.14 \\
\hline PG6 & 1.50 & 327.17 & 329.7 & 254.6 & 0.99 & 1.29 & 1.29 \\
\hline PG7 & 2.00 & 260.65 & 243.9 & 225.3 & 1.07 & 1.16 & 1.08 \\
\hline PG8 & 2.00 & 262.92 & 262.9 & 223.7 & 1.00 & 1.18 & 1.18 \\
\hline PG9 & 2.50 & 228.05 & 207.1 & 202.9 & 1.10 & 1.12 & 1.02 \\
\hline PG10 & 2.50 & 236.54 & 214.7 & 202.2 & 1.10 & 1.17 & 1.06 \\
\hline PG11 & 3.25 & 217.90 & 182.0 & 180.1 & 1.20 & 1.21 & 1.01 \\
\hline PG12 & 3.25 & 215.33 & 182.8 & 180.0 & 1.18 & 1.20 & 1.02 \\
\hline PG13 & 1.00 & 357.33 & 370.6 & 258.5 & 0.96 & 1.38 & 1.43 \\
\hline PG14 & 1.50 & 279.47 & 285.5 & 209.9 & 0.98 & 1.33 & 1.36 \\
\hline PG15 & 1.50 & 350.36 & 333.7 & 259.1 & 1.05 & 1.35 & 1.29 \\
\hline PG16 & 1.50 & 382.36 & 344.3 & 265.1 & 1.11 & 1.44 & 1.30 \\
\hline PG17 & 1.50 & 414.52 & 350.9 & 269.4 & 1.18 & 1.54 & 1.30 \\
\hline PG18 & 1.50 & 421.83 & 360.2 & 295.4 & 1.17 & 1.43 & 1.22 \\
\hline PG19 & 1.50 & 421.53 & 365.3 & 277.1 & 1.15 & 1.52 & 1.32 \\
\hline \multirow{2}{*}{\multicolumn{5}{|c|}{$\begin{array}{r}\text { Average } \\
\text { Standard deviation }\end{array}$}} & 1.07 & 1.26 & 1.18 \\
\hline & & & & & 0.08 & 0.16 & 0.14 \\
\hline \multicolumn{5}{|r|}{ Maximum } & 1.20 & 1.54 & 1.43 \\
\hline \multicolumn{5}{|r|}{ Minimum } & 0.95 & 0.91 & 0.95 \\
\hline
\end{tabular}

\subsubsection{Elevated temperature}

The plate girders analysed at normal temperature were subjected to a $500^{\circ} \mathrm{C}$ uniform temperature. The comparison between the numerical results and the design procedures is presented in Table 14. In contrast to what happened at normal temperature, the numerical results are on the unsafe side when compared to the design procedures. The average $\mathrm{VSAFIR}_{\text {SEC3 }}$ ratio is 0.88 and the standard deviation is 0.11 . It shows that the application of the reduction factors for the stress-strain relationship of stainless steel at elevated temperatures to the design procedures at normal temperature is not a conservative approach and new design expressions to predict the ultimate shear strength in stainless steel plate girders under fire should be developed. 
Table 14 - Ultimate shear strength at elevated temperature

\begin{tabular}{|c|c|cc|c|}
\hline Designation & a/hw & $\begin{array}{c}\mathrm{V}_{\text {SAFIR }}[\mathrm{kN}] \\
(1)\end{array}$ & $\begin{array}{c}\mathrm{V}_{\mathrm{EC} 3}[\mathrm{kN}] \\
(2)\end{array}$ & $\begin{array}{c}\text { Safety factor } \\
(1) /(2)\end{array}$ \\
\hline PG1 & 0.50 & 283.1 & 399.3 & 0.71 \\
PG2 & 1.00 & 222.8 & 221.8 & 1.00 \\
PG3 & 1.50 & 163.9 & 183.0 & 0.90 \\
PG4 & 2.00 & 133.8 & 165.2 & 0.81 \\
PG5 & 1.50 & 165.1 & 196.3 & 0.84 \\
PG6 & 1.50 & 185.1 & 194.0 & 0.95 \\
PG7 & 2.00 & 133.6 & 172.4 & 0.77 \\
PG8 & 2.00 & 145.9 & 170.9 & 0.85 \\
PG9 & 2.50 & 115.6 & 155.2 & 0.75 \\
PG10 & 2.50 & 119.4 & 154.7 & 0.77 \\
PG11 & 3.25 & 103.5 & 137.7 & 0.75 \\
PG12 & 3.25 & 103.8 & 137.6 & 0.75 \\
PG13 & 1.00 & 214.8 & 192.9 & 1.11 \\
PG14 & 1.50 & 159.1 & 159.1 & 1.00 \\
PG15 & 1.50 & 187.7 & 197.4 & 0.95 \\
PG16 & 1.50 & 194.1 & 202.0 & 0.96 \\
PG17 & 1.50 & 197.8 & 205.3 & 0.96 \\
PG18 & 1.50 & 201.7 & 225.6 & 0.89 \\
PG19 & 1.50 & 205.7 & 211.2 & 0.97 \\
\hline & & & Average & 0.88 \\
& & & Standard deviation & 0.11 \\
& & & Maximum & 1.11 \\
& & & Minimum & 0.71 \\
\hline
\end{tabular}

\section{Summary and conclusions}

This paper studied the ultimate shear strength of stainless steel plate girders at normal temperature and in case of fire. The main objective was to develop a solid numerical model duly validated with experimental tests. In the future, this model will allow performing solid parametric numerical studies about the influence of different parameters on the ultimate shear strength of stainless steel plate girders subjected to shear buckling at elevated temperatures, which will allow the development of fire safe design procedures that will fill the absence of guidance in Part 1-2 of EC3. With this purpose, a total of 34 experimental tests were numerically modelled using SAFIR 
software. Comparisons between the numerical and the experimental results were performed. Furthermore, the numerical results provided by SAFIR were also compared to the results of the numerical modelling performed by the authors of the experimental tests. For the analysed stainless steel plate girders a good agreement between the experimental tests and the results from the numerical analyses with SAFIR was observed.

Despite the difference between the constitutive laws of stainless steel, of Part 1-4 and Part $1-2$ at $20^{\circ} \mathrm{C}$, it is possible to observe that the results presented in this paper for shear buckling in stainless steel plate girders very good. In fact, failure by shear buckling occurs for small strains, where the differences between the stainless steel constitutive laws of Parts 1-4 and 1-2 of EC3 at $20^{\circ} \mathrm{C}$ are not significant, as shown in Figure 10.

It was observed that the numerical model developed in SAFIR provides a good approximation to the actual behaviour of stainless steel plate girders and it is able to accurately predict the ultimate shear strength of stainless steel plate girders under shear, as well as their failure modes.

It was analysed the influence of the initial imperfections on the bearing capacity of stainless steel plate girders affected by shear buckling. It was concluded that the geometric imperfections must be always taken into account in the numerical modelling at both normal and elevated temperature, being $t_{w} / 10$ an appropriate value for the modelling of experimental tests. Regarding residual stresses, it was observed that the consideration of the residual stresses at both normal and elevated temperature did not cause a significant reduction on the ultimate strength of stainless steel plate girders. 
The accuracy of the EC3 design procedures at normal temperature and adapted to fire design was analysed. It was observed that the current formulation of the Rotated Stress Field method for stainless steel elements is conservative at normal temperature. On the other hand, the adaptation of these expressions to fire design, through the application of the reduction factors for the mechanical properties of stainless steel at elevated temperature, is not conservative and new design expressions must be proposed to perform the safety evaluation of stainless steel structural elements subjected to shear buckling in fire situation.

\section{Acknowledgments}

This research work was partially funded by the Portuguese Government through the FCT (Foundation for Science and Technology) under the PhD grant SFRH/BD/85563/2012 (POPH/FSE funding) awarded to the first author. The authors would also like to thank to Professor Sung Lee for the data and valuable information provided which was helpful to the development of this work. 


\section{Notation}

$\begin{array}{ll}\text { a } & \text { transverse stiffeners spacing } \\ \text { bf } & \text { flange width } \\ \text { bls } & \text { longitudinal stiffener width } \\ \text { e } & \text { transverse stiffeners spacing of the rigid end post } \\ \text { E } & \text { Young's modulus } \\ \mathrm{h}_{\mathrm{w}} & \text { web depth } \\ \mathrm{L} & \text { girder length } \\ \mathrm{P} & \text { ultimate load } \\ \mathrm{PG} & \text { plate girder } \\ \mathrm{t}_{\mathrm{w}} & \text { web thickness } \\ \mathrm{t}_{\mathrm{f}} & \text { flange thickness } \\ \mathrm{t}_{\mathrm{s}} & \text { transverse stiffeners thickness } \\ \mathrm{t}_{\mathrm{s}} & \text { longitudinal stiffeners thickness } \\ \sigma_{0.2} & \text { proof strength at } 0.2 \% \\ \sigma_{\mathrm{m}} & \text { ultimate strength }\end{array}$




\section{References}

[1] Gardner L. The use of stainless steel in structures. Progress in Structural Engineering and Materials, 2005; 7(2): 45-55. doi: 10.1002/pse.190

[2] Euro Inox and Steel Construction Institute. Design manual for structural stainless steel, 3rd edition, Euro Inox and Steel Construction Institute, London, 2005.

[3] Olsson A.. Stainless steel plasticity-material modelling and structural applications. Doctoral thesis. Lulea University of Technology, Sweden, 2001.

[4] Höglund T. Shear buckling resistance of steel and aluminium plate girders. ThinWalled Structures, 1997; 29(1-4): 13-30. doi:10.1016/S0263-8231(97)00012-8

[5] CEN. Eurocode 3: Design of Steel Structures. Part 1-4: General rules Supplementary rules for stainless steels, Brussels, Brussels, 2006.

[6] Kodur V, Aziz E, Dwaikat M. Evaluating fire resistance of steel girders in bridges. Journal of Bridge Engineering, 2013; 18(7): 633-643. http://dx.doi.org/10.1061/(ASCE)BE.1943-5592.0000412

[7] Kodur VK, Naser MZ. Effect of shear on fire response of steel beams. Journal of Constructional Steel Research, 2014; 97: 48-58. doi:10.1016/j.jcsr.2014.01.018

[8] Garlock M, Payá-Zaforteza I, Kodur V, Gu L. Fire Hazard in Bridges: Review, Assessment, and Repair Strategies. Engineering Structures, 2011; 35: 89-98. doi:10.1016/j.engstruct.2011.11.002

[9] Real E., Mirambell E., Estrada I. - Shear response of stainless steel plate girders. Engineering Structures, 2007; 29: 1626-1640. doi:10.1016/j.engstruct.2006.08.023 
[10] Estrada I., Real E., Mirambell E. - General behaviour and effect of rigid and non-rigid end post in stainless steel plate girders loaded in shear. Part I: Experimental study. Journal of Constructional Steel Research, 2007; 63(7): 970-984. doi:10.1016/j.jcsr.2006.08.009

[11] Estrada I. - Shear design of stainless steel plate girders. Doctoral thesis. Polytechnic University of Catalunya, Spain, 2005.

[12] Saliba N., Gardner, L. - Experimental study of the shear response of lean duplex stainless steel plate girders. Engineering Structures, 2013; 46: 375-391. doi:10.1016/j.engstruct.2012.07.029

[13] Saliba N., Real E., Gardner, L. - Shear design recommendations for stainless steel plate girders. Engineering Structures, 2014; 59: 220-228. doi:10.1016/j.engstruct.2013.10.016

[14] Franssen JM. SAFIR, a thermal/structural program modelling structures under fire. Engineering Journal, 2005; 43(3): 143-58. http://hdl.handle.net/2268/2928

[15] Franssen JM. User’s manual for SAFIR - A computer program for analysis of structures subjected to fire: Department ArGEnCO. University of Liége, 2011.

[16] CEN. Eurocode 3: Design of Steel Structures. Part 1-2: General rules Structural fire design, Brussels, 2005.

[17] Rasmussen KJR. Full-range stress-strain curves for stainless steel alloys. Journal of Constructional Steel Research, 2003; 59(1): 47-61. doi:10.1016/S0143974X(02)00018-4 
[18] Arrayago I, Real E, Gardner L. Description of stress-strain curves for stainless steel alloys. Materials and Design, 2015; 87: 540-552. doi:10.1016/j.matdes.2015.08.001

[19] CAST3M. CAST3M is a research FEM environment; its development is sponsored by the French Atomic Energy Commission, 2012. <http://wwwcast3m.cea.fr/>.

[20] Couto C, Vila Real P, Lopes N. RUBY, an interface software for running a buckling analysis of SAFIR models using Cast3M, University of Aveiro, 2013.

[21] Hancock GJ. Nonlinear analysis of thin sections in compression. Journal of the Structural Division, 1981; 107(3): 455-71.

[22] Quiel S, Garlock M. Calculating the buckling strength of steel plates exposed to fire. Thin-Walled Structures, 2010; 48: 684-95. doi:10.1016/j.tws.2010.04.001

[23] Lopes N, Vila Real P, Simões da Silva L, Franssen JM. Numerical modelling of thin-walled stainless steel structural elements in case of fire. Fire Technology, Springer, 2010; 46(1): 91-08. doi: 10.1007/s10694-009-0084-X

[24] Lopes N, Vila Real P. Resistance of stainless steel structural elements at normal temperature using the constitutive laws of Parts 1-2 and 1-4 of EC3: comparative study (in Portuguese). Congress on Numerical Methods in Engineering, Coimbra, 2011.

[25] ABAQUS/Standard - User's manual. Rhode Island (USA): Hibbit, Karlsson and Sorensen Inc., 2002.

[26] Prachar M, Lopes N, Couto C, Jandera M, Vila Real P, Wald F. Lateral torsional buckling of class 4 steel plate girders under fire conditions: experimental and numerical 
comparison, COST Action TU0904 - Benchmarks studies, Experimental validation of numerical models in fire engineering, pp. 21-33, CTU Publishing House, Czech Technical University in Prague, 2014.

[27] Talamona D, Franssen JM. A Quadrangular Shell Finite Element for Concrete and Steel Structures Subjected to Fire. Journal of Fire Protection Engineering, 2005; 15(4): 237-64. doi: 10.1177/1042391505052769

[28] CEN. EN 1090-2:2008+A1, Execution of steel structures and aluminium structures - Part 2: Technical requirements for steel structures, 2011.

[29] ECCS. Manual on stability of steel structures. Publication no. 22. ECCS Technical Committee 8 - Structural Stability, 1976.

[30] ECCS. Ultimate limit state calculation of sway frames with rigid joints. Publication no. 33. ECCS - Technical Committee 8 - Structural Stability, Technical Working Group 8.2 - System, 1984.

[31] CEN. Eurocode 3: Design of Steel Structures. Part 1-5: Plated Structural Elements, Brussels, 2006.

[32] Franssen JM, Vila Real P. Fire Design of Steel Structures, ECCS Eurocode Design Manuals, Brussels: Ernt \& Sohn A Wiley Company, 1st Edition, 2010. 